Winter 1-2021

\title{
Occupational Therapist's Role in Addressing Transition Support Through Life Skills
}

\author{
Rupa Parikh \\ University of St. Augustine for Health Sciences \\ DOI: https://doi.org/10.46409/sr.SPU06932
}

Follow this and additional works at: https://soar.usa.edu/capstones

Part of the Occupational Therapy Commons, Secondary Education Commons, and the Vocational Education Commons

\section{Recommended Citation \\ Parikh, R. (2021). Occupational Therapist's Role in Addressing Transition Support Through Life Skills. [Doctoral project, University of St Augustine for Health Sciences]. SOAR @ USA: Student Capstone Projects Collection. https://doi.org/10.46409/sr.SPU06932}

This Capstone is brought to you for free and open access by the Student Research at SOAR @ USA. It has been accepted for inclusion in Student Capstone Projects by an authorized administrator of SOAR @ USA. For more information, please contact soar@usa.edu, erobinson@usa.edu. 
Occupational Therapist's Role in Addressing Transition Support Through Life Skills

\author{
Rupa D Parikh \\ Department of Occupational Therapy, University of St. Augustine for Health Sciences
}

A Capstone Presented in Partial Fulfillment of the Requirement for the Degree of DOCTOR OF OCCUPATIONAL THERAPY University of St. Augustine for Health Sciences

January 2021 


\title{
Occupational Therapist's Role in Addressing Transition Support Through Life Skills
}

\author{
Rupa, D, Parikh
}

Department of Occupational Therapy, University of St. Augustine for Health Sciences has been approved

January 2021

APPROVED:

Susan MacDermott, OTD, OTR/L, Doctoral Coordinator

Becki Cohill, OTD, OTR/L, Doctoral Coordinator

Erin Schwier, EdD, OTD, OTR/L, Program Director

ACCEPTED AND SIGNED:

\begin{tabular}{|c|c|}
\hline $\begin{array}{l}\text { Susan MacDermott, } \\
\text { OTD, OTR/L }\end{array}$ & 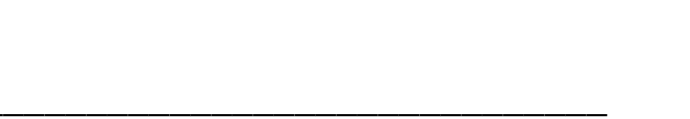 \\
\hline \multicolumn{2}{|c|}{ Susan MacDermott, OTD, OTR/L, Doctoral Coordinator } \\
\hline \multicolumn{2}{|c|}{ Becki Cohill OTD OTR/L L } \\
\hline \multicolumn{2}{|c|}{ Becki Cohill, OTD, OTR/L, Doctoral Coordinator } \\
\hline & VIer $\begin{array}{c}\text { Digitally signed by Erin Schwier } \\
\text { DN: cn=Erin Schwier, o=USAHS, ou, } \\
\text { email=eschwier@usa.edu, c=US }\end{array}$ \\
\hline
\end{tabular}




\section{Table of Contents}

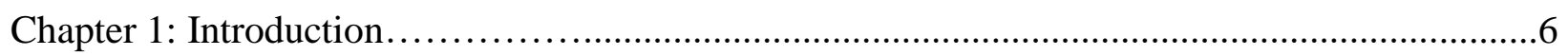

Background...........................................................6

Statement of the Problem.......................................................... 10

Purpose Statement.....................................................10

Rationale of Proposed Project.............................................11

Significance of Proposed Project............................................ 13

Objectives............................................................ 13

Definition of Terms..................................................... 14

Assumptions.............................................................14

Limitations/Delimitations............................................... 15

Chapter 2: Literature Review.................................................... 15

Difficulties in the Transition Process for High Risk Youth............................ 16

Benefits of Life Skills Transition Programs.......................................17

Occupational Therapists' Role in Transition Programs................................19

Barriers to Occupational Therapists' Participation in Transition Services................20

Literature Review Conclusion.................................................21

Chapter 3: Project Description..................................................... 21

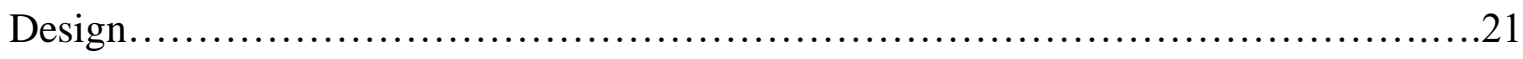

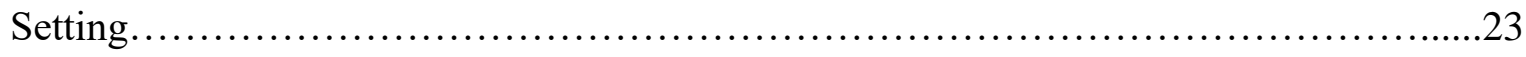

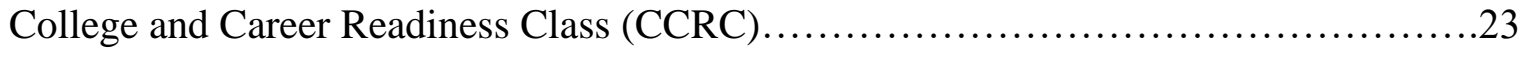

Summer Health Class...................................................... 30

Future Plans for Evaluation....................................................... 


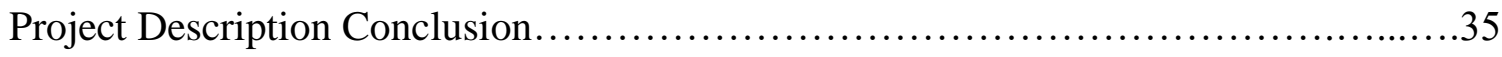

Chapter 4: Evaluation of Development................................................

CCRC Life Skills Pre- and Post- Survey Quantitative Data...........................35

CCRC Life Skills Pre- and Post- Survey Qualitative Data ..........................37

Health Class Survey Quantitative Data........................................39

Health Class Survey Qualitative Data.........................................41

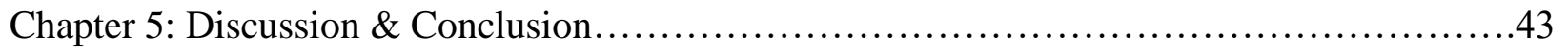

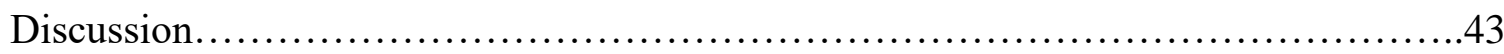

Future Development of Program ...........................................45

Implications for Occupational Therapy....................................46

Sustainability of Life Skills Program.......................................47

Conclusion...........................................................47

References........................................................................ 49

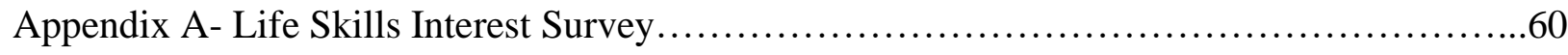

Appendix B- Survey Questions for Staff..........................................61

Appendix C- Life Skills Pre-Survey ..............................................62

Appendix D- Life Skills Post-Survey.............................................63

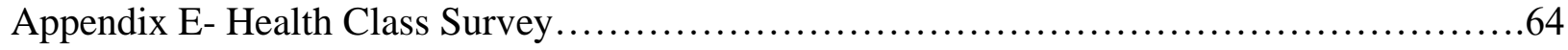

Appendix F- Self-Care Outline.................................................65

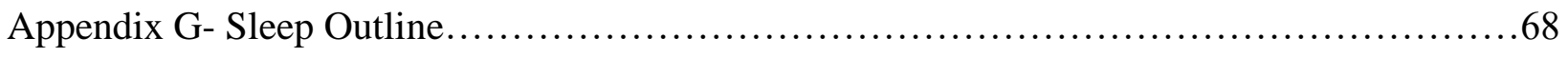

Appendix H- Conflict Resolution................................................... 70

Appendix I- Food \& Nutrition.................................................... 72 


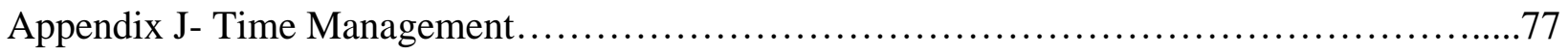

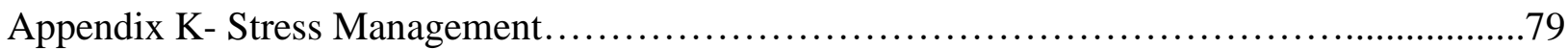

Appendix L- Independent Living and Home Management................................82

Appendix M- Self-Care: Health Class...............................................86

Appendix N- Food \& Nutrition: Health Class ....................................... 87

Appendix O- Time Management: Health Class........................................91

Appendix P- Stress Management: Health Class..........................................93

Appendix Q- Life Skills Inventory Independent-Living Skills Assessment Tool...............97 


\section{Chapter 1: Introduction}

The purpose of the proposal is to outline the various components of the vision for my capstone project focused on the transition from high school to postsecondary education for highrisk youth. In this proposal I will discuss the background of the project, the problem statement, the purpose, rationale, and significance of the project and my preliminary project objectives.

\section{Background}

Literature has shown that many young individuals find the transition from high school to post-secondary education challenging (Lindsay et al., 2016). This transition from school to adult life can be defined as "involving actions coordinated to prepare for or facilitate change, such as from one functional level to another, from one life stage to another, from one program to another, or from one environment to another" (American Occupational Therapy Association [AOTA], 2000, p. 866). Issues that arise in this time period include establishing new adult roles such as work, experiencing satisfactory personal and social relationships, participating in postsecondary education, becoming involved in the community, maintaining a home, as well as finding ones' self-identity (Mosey, 1970). High risk youth such as those with disabilities have been shown to have greater difficulties with this transition (Lindsay et al., 2016).

Studies have shown that individuals with disabilities have lower rates of high school graduation, postsecondary education, and residential independence (Spencer et al., 2003). For example, only $59 \%$ of youth with disabilities between the ages of 18-21 attended post-secondary education, compared to $72 \%$ of youth without a disability (Lindsay et al., 2016). Although many students choose the employment path after high school, an increasing amount of jobs in the U.S. require education beyond high school (Royster et al., 2015). Many high school students with disabilities entering college display deficit in the knowledge, skills, or habits needed to succeed 
(Venezia et al., 2013). There can be many reasons for this lack of college readiness including a disconnect between what high schools teach and what colleges expect, disparities in socioeconomic status, peer influences, and parental expectations (Venezia et al., 2013).

The transition from high school to college can be difficult for individuals with disabilities due to the higher demands placed on students. For example, college students are required to complete large amounts of reading, stay attentive throughout long lectures, and take multiple exams in a short period of time (Hamblet, 2014). A study reports that students with attention deficit hyperactivity disorder or learning disabilities struggle with the transition to college due to deficits in their organizational skills, academic coping strategies, executive functions, and sustained attention (Hamblet, 2014). These challenges can affect this population of students more than the average student because their disabilities can affect learning, planning, and concentration, which are all critical to success in academics in college (Hamblet, 2014).

An area that youth with disabilities are also shown to have difficulties with during the transition from high school to college include life skills such as communication, independent living, and financial literacy (Swank \& Huber, 2013). The path of post-secondary education requires an individual to have transitional life skills. Teaching life skills is appropriate for all students, however, even more necessary for youth with disabilities. Youth with disabilities have been shown to lack opportunities to develop life skills and experiences concerning social interaction, personal growth, and decision making (King et al., 2016). Although life skills can be a critical component to the success of individuals with disabilities, research suggests a decreasing emphasis on the acquisition of life skills in school (Bouck, 2010). There has been a large shift to educating students with disabilities on academic content rather than preparing them for 
participation and independence in the community (i.e. independent living, daily living skills) (Bouck, 2010).

Many individuals with disabilities struggle with life skills such as communication and socialization, making it difficult to form meaningful relationships with other students (Ashbaugh et al., 2017). Adjusting to the social pressure of college and independent living has been shown to be the most challenging areas for college students with disabilities due to the requirement to demonstrate advanced social skills to succeed (Ashbaugh et al., 2017). Students with disabilities may struggle with the social interactions in a new place rather than the cognitive abilities necessary in college (Ashbaugh et al., 2017). Social deficits in young adults with disabilities has been shown to impact participation and success in higher education, which has been linked to self-confidence, quality of life, personal skill building, and future employment (Ashbaugh et al., 2017). Overall, it is imperative that high-risk youth are taught these critical life skills which can help them succeed in the transition to postsecondary education.

Occupational therapists are client-centered, occupation-based professionals that could contribute significantly to a successful transition to postsecondary education for high risk youth (Eismann et al., 2017). They support the integration of daily living skills in order to achieve independence and autonomy (Abaoğlu et al., 2017). Occupational therapists support clients in creating individualized goals through life skills training (Abaoğlu et al., 2017). Some of these goals include learning skills such as meal preparation, banking/budgeting, community assertiveness, and shopping (Abaoğlu et al., 2017). Overall, occupational therapists offer a holistic approach to enable or enhance participation in daily activities (Abaoğlu et al., 2017).

Occupational therapists can play an important role in the transition process by helping high-risk youth achieve the independence required for college (Eismann et al., 2017). The 
benefits of including occupational therapists in the transition process are facilitating students' involvement in early paid work experiences, helping students prepare for IEP meetings, giving instruction in social competence and daily living, and providing consultation on assistive technology needs (Eismann et al., 2017). Occupational therapists can be a unique asset to transition teams due to their unique role of providing occupation-based evaluation and intervention (Spencer et al., 2003). They are able to use real life tasks and task analysis to assist students with developing functional living skills (Spencer et al., 2003). Occupational therapists involve the students in planning transition outcomes while using relevant school and community environments (Spencer et al., 2003). Occupational therapists can not only help facilitate learning of functional living skills, they are also able to educate parents and staff members on this topic. Research has also suggested that occupational therapists may contribute to transition teams by providing interventions designed to improve self-care skills, and social skills (Eismann et al., 2017). These interventions can help improve outcomes when connected to relevant postsecondary education and employment goals (Eismann et al., 2017). Occupational therapists can also aide in students' participation in the community as a strong connection has been found between participation in community-based activities and successful transition outcomes (Newman et al., 2011).

Despite the large amount of benefits occupational therapy can offer to the transition service process, practice in this area is extremely limited (Eismann et al., 2017). Studies have found that occupational therapists provide less than one fifth of transition services in high schools for students with disabilities (Spencer et al., 2003). Occupational therapists may evaluate, treat, and recommend services for youth ages 3-21, however, research has shown that services are provided more to preschool and elementary school students than high school 
students (Spencer et al., 2003). Some barriers to an occupational therapists' participation in transition services include funding, lack of interagency planning, and lack of parent participation (Spencer et al., 2003). Another barrier to the participation in transition services can be a lack of utilization and understanding of the role occupational therapists may play (Kardos \& White, 2005). Because many occupational therapists are employed by means of a contract with the school district or self-employed, they may be seen as consultants who should only be utilized when employees cannot provide services (Spencer et al., 2003). Occupational therapists may be seen as a higher cost provider, which could impact their utilization in the transition process (Spencer et al., 2003). A lack of knowledge of assessment tools for transition planning and large caseload could also prove to be barriers to occupational therapists' participation in transition services (Kardos \& White, 2005). It is important that the benefits and role of occupational therapists in transition services be emphasized in order to ensure high risk students are meeting their full potential in the transition process.

\section{Statement of the Problem}

The transition period from high school to postsecondary education has been shown to be a difficult time for youth, especially for those with disabilities. The use of occupational therapists in the area of transition services for these youth can positively affect their ability to attend postsecondary education. Guidance and support are needed in preparing these individuals for future success in the transition to postsecondary education.

\section{Purpose Statement}

The limited participation of occupational therapists in the area of transition from high school to postsecondary activities may be impacting students' ability to reach their full potential. This capstone project aims to assess the needs of students with disabilities in order to identify 
occupational limitations in the area of life skills needed for the transition to postsecondary education. Through identification of problem areas, a detailed program will be created and implemented to meet the needs of this population during this difficult time period.

\section{Project Rationale}

This project is necessary in order to enable high-risk students to successfully transition to postsecondary education. Developmentally, the transition into young adulthood can bring up many issues such as self-identity (Erikson, 1997) and establishing new adult roles such as home maintenance, social, community, and family (Levinson, 1978; Mosey, 1986). Specific areas that may require intervention include postsecondary education, and life skills such as money management. This project is guided by the lifespan developmental frame of reference, which focuses on assisting clients with transitional tasks (Levinson, 1978). According to this frame, if an individual's attempts to progress developmentally are met with success, motivation will remain intact, however, if there are repeated failures to keep up with peers this may discourage an individual from trying (Levinson, 1978). Development of a transition program based specifically on the needs of high-risk students will allow for the development of skills necessary for successful occupational participation in postsecondary activities.

This project is also guided by the Person-Environment-Occupation-Performance Model (PEOP), which emphasizes how an individuals' behaviors and environment are interconnected (Baum \& Christiansen, 2005). The PEOP model "studies the health conditions that support or impede performance, environments that allow and/or restricts performance, and an individual's personal profile that include needs, preferences, and goals" (Baum \& Christiansen, 2005, p.128). By following this model, an occupational therapist will be able to view their client as someone whose performance can be influences by their health condition and environmental demands 
(Christiansen \& Baum, 2005; Law et al., 1996). This project focuses on learning about how an individuals' disability or mental health condition is impacting their ability to successfully transition to college, as well as how their environment is helping or hindering this transition process. For example, students spend much of their time in the school environment, therefore, it is important to make these environments more supportive. During transitional stages, young adults are often full of self-doubt, experience high anxiety, and may display radical changes in their attitudes, activity patterns, and lifestyle (Baum \& Christiansen, 2005). The addition of new occupations such as finances and home maintenance in a new social, physical (e.g. dorms, apartments, campus facilities) and cultural environment could have a large effect on an adolescents' performance (Baum \& Christiansen, 2005). This transition from high school to college is an important life stage with large changes that should be addressed prior to college (Baum \& Christiansen, 2005). The goal for this project is to help prepare students to cope with challenges that may come up due to their disabilities and provide a supporting environment to help ease this transition.

Transition services have also been identified as one of the eight Standards of Practice for Occupational Therapy and emphasizes support in major life areas such as activities of daily living, education, work, play, leisure, and social participation (AOTA, 2002). Through the implementation of a transition program with high-risk youth, occupational therapists will promote engagement in major life areas as well as attend to the five critical aspects of performance which include performance skills, performance patterns, client factors, activity demands, and contexts (AOTA, 2002). 


\section{Project Significance}

Developing a program to support the transition of youth into adulthood is a pressing issue which can impact clinical practice, policy, and research (Nguyen et al., 2018). Therefore, determining ways to optimize services for transitioning youth should be a priority for healthcare systems (Nguyen et al., 2018). This project is significant because it will enable young individuals to gain the functional life skills necessary to succeed in postsecondary education. Implementation of this program will potentially help students increase their levels of selfdetermination, which refers to their ability to make choices and decisions about their life without external influence or interference (Michaels \& Orentlicher, 2004). Studies report that students with disabilities who had higher levels of self-determination and were in a transition process from high school to postsecondary activities were significantly more likely to be living independently and have greater financial independence than their peers with low selfdetermination (Michaels \& Orentlicher, 2004). This project will also allow other occupational therapists to utilize these findings to advocate for their role in the transition process as an emerging area of practice (Eismann et al. , 2017).

\section{Project Objectives}

\section{Learning Objectives}

I. To determine outcome measures appropriate for determining postsecondary activity success in transitional life skills

II. To determine common themes of occupational limitations in the transition process through research and completion of a needs assessment in the area of life skills

III. To gather more information through research on transition from high school to college and successful transition programs focusing on life skills 
IV. To identify transition programs offered at various schools in San Diego County and become familiar with the services they provide and areas for improvement

\section{Outcome Objectives}

I. To assess needs in the area of life skills of high-risk students as they transition from school to postsecondary education or employment

II. To develop a detailed proposal for development of a life skills program to meet the identified needs for high-risk students

\section{Definition of Terms}

Life Skills are abilities that help individuals deal with challenges in life and help promote physical, mental, and emotional well-being and competence (Abaoğlu et al., 2017). Life skills can include a variety of abilities that help enable an individual to perform tasks such as personal care, shopping, and community participation (Abaoğlu et al., 2017).

High-risk youth will refer to populations of youth in high school that are susceptible to having difficulties with the postsecondary education transition. This includes youth with disabilities but is not restricted to this population.

Transition will be defined as change from one life stage to another (AOTA, 2000, p. 866). For the purposes of this project, the main focus will be the transition from high school to college which will be referred to as postsecondary education.

\section{Assumptions}

Based on research, some assumptions have been drawn that are important to acknowledge. This project assumes that high risk youth display deficits in life skills that can affect their ability to successfully transition from high school to college. It also assumes that these high-risk youth are interested in pursuing postsecondary education. This transition program 
is being created for use at various schools based on the assumption that they would be interested in implementing a transition program. Another delimitation includes the decision not to narrow down the population to those with disabilities or a certain type of disability, making it inclusive, yet possibly too broad.

\section{Limitations and Delimitations}

Due to the fact that this project is being created and implemented at one school, Winston School, there are a few limitations that should be discussed. One limitation of creating and implementing this program at Winston School is that it may not be applicable to other schools that may have a different population of students or limited amount of resources. Another limitation that cannot be controlled is that certain students may not want to participate in the transition program. We may also be limited in the age range of the students due to this project taking place at a high school. There are also a few delimitations of this project such as the fact that it is being implemented only in a school setting with a certain population of high school youth. Another delimitation includes the decision not to narrow down the population to those with disabilities or a certain type of disability, making it inclusive, yet possibly too broad. This program will also be focused on teaching a certain set of life skills as there is not enough time to cover all the various types.

\section{Chapter 2: Literature Review}

There is an abundance of literature to support this proposed project on postsecondary education transition programs. Literature has shown that high-risk youth, such as those with disabilities or mental health challenges, have a difficult time with the transition from high school to post-secondary education. Transition programs utilizing occupational therapists have been shown to make a positive impact for these high -risk youth, however, they are highly 
underutilized. A review of the literature displays a need for transition programs utilizing occupational therapists to help ease the transition for high-risk youth from high school to postsecondary education.

\section{Difficulties in the Transition Process for High Risk Youth}

Literature has shown that a greater number of high-risk students, such as those with disabilities, are graduating from high school and entering postsecondary education (Gil, 2007). Youth with disabilities have been shown to encounter difficulties that may negatively impact their progress in the traditional 4-year college environment (Hamblet, 2014). These students report difficulty in feeling overloaded with work, prioritizing, study skills, test taking and preparation, note taking, and organizing (Hamblet, 2014). This may suggest that youth with disabilities are not being equipped with the tools and skills necessary to successfully transition from high school to college.

There are also other populations of high-risk youth that may be affected by the transition from high school to postsecondary education. One high-risk group that could face challenges during this time of transition is youth with mental health challenges such as depression or anxiety. There are many studies that describe the association between mental health early in life and educational attainment later in life (Eisenberg et al., 2009). One study assessing early-life mental health found that early-onset (before adulthood) depression is associated with less schooling (Eisenberg et al., 2009). This study also found that a large number of early-onset psychiatric disorders are associated with early termination of school (Eisenberg et al., 2009). In addition to the challenges faced with a transition from high school to college, youth with mental health challenges may face additional obstacles such as medication management, counseling appointments, academic accommodations, emotional variability, and sleep difficulty (Fier \& 
Brzezinski, 2010). Another study revealed students with social anxiety are shown to be at higher risk of avoiding postsecondary education and of encountering academic problems such as lower grades, class absences, and fear of public speaking (Nordstrom et al., 2014). Based on research, youth with mental health challenges are at high risk of having difficulties with the transition to college and require support in high school to help ease this process.

One component that was found to affect a smooth transition from high school to postsecondary education for this population was a knowledge of the process required to obtain services. Many high-risk youth struggle with gaining knowledge of the process to access services in the postsecondary setting, which could affect their chances of receiving the services they need (Gil, 2007). The more preparation these students have in this area prior to beginning the transition from high school to college, the greater likelihood of a smooth transition (Gil, 2007).

\section{Benefits of Life Skills Transition Programs}

Transition programs can help high-risk youth prepare for postsecondary activities such as college, community integration, and independent living after high school (Spencer et al., 2003). Research has supported the benefits of transition programs in helping high-risk youth successfully transition into postsecondary education (Benz et. al, 2000). Transition services can help students with disabilities prepare for postsecondary activities such as further education, independent living, and community integration (Spencer et al., 2003). Establishing a secondary general education curriculum that addresses comprehensive needs of adolescents (e.g., academic,

life-skill, and career) through school and community-based activities should be a goal in order to help students with the transition from high school to college (Benz et. al, 2000).

A large component hindering successful transition found throughout the literature was a deficit in life skills required in college. Life skills are considered "skills or tasks that contribute 
to the successful, independent functioning of an individual in adulthood" (Bouck, 2010, p. 1093). Many studies have shown the positive effects of including life skills education in high school curriculum. One study found that students who participated in their transition program involving life skills showed an increase in graduation rates, engagement in employment or postsecondary education, and higher wages (Benz et al., 2000). There have also been studies which have shown negative outcomes with the lack of certain life skills. One study notes that inadequate transportation skills negatively impacted areas of a students' adult life including employment, community access, and independent living (Salzberg et al., 1988). Life skills can start to be integrated into curriculum as early as preschool and continue to develop through high school (King, et al., 2016). It is important to select life skills activities that are age appropriate and match the interest level of the individual student (King et.al, 2016). Life skills can also be integrated into academic areas in order to emphasize the relationship of the academic activity to everyday activities (King et.al, 2016). These skills are best taught in natural settings by helping students understand how certain skills can be used in real life contexts (King et.al, 2016). Life skills necessary for transitioning to an individual's next environment are essential components in transition education and should be based on their personal situations, interests, and abilities (King et.al, 2016).

Life skills transition programs have been shown to be effective, however, there are several gaps that have been discovered through literature. Based on a narrative systematic review of life skills education effectiveness, life skills transition programs are lacking in certain areas. For example, life-skills content should be taught through more skill-based activities to ensure skills are developed (Nasheeda et al., 2018). This review also reports that many life skills programs are structured as short-term interventions rather than ongoing activities, and lack 
emphasis on individual learning (Parvathy \& Pillai, 2015; Teyhan et al., 2016; Tuttle et al., 2006). Therefore, there needs to be a greater emphasis on creating ongoing and sustainable life skills transition programs through systematic planning, implementation, and evaluation (UNICEF, 2012). This systematic review also found that a variety of teaching methods needs to be used to ensure student involvement and understanding of life skills (Nasheeda et. al, 2018). The content needs to be delivered with an emphasis on skill development (Nasheeda et. al, 2018). It is important to consider these gaps in the literature when creating a life skills transition program.

\section{Occupational Therapists' Role in Transition Programs}

A student's transition to postsecondary education and community settings can be considered a marker of success (Eismann et al., 2017). Transition services should target successful participation and independence in these areas (Eismann et al., 2017). It has been shown that high-risk youth are less likely to be enrolled in postsecondary education and engaged in community activities in the years after the transition to adulthood (Wehman, 2013). These areas are important for youth in the transition process and occupational therapists are experts at helping youth maximize independence in these areas (Cleary et al., 2015).

Research demonstrates the positive role that occupational therapists can play in transition programs. A review of the literature contributes to the understanding that the benefits of occupational therapists working on the transition team include:

- Occupational therapists are experts in task analysis and can help high-risk youth adapt to their roles as students (Eismann et al., 2017) 
- Occupational therapists are able to provide occupation-based evaluation and intervention, utilizing functional, real-life tasks to help students develop functional living skills (Spencer et al., 2003)

- Occupational therapists may develop prevocational programs, facilitate functional living skills development, modify environments, and educate parents and staff (Spencer et al., 2003)

- Occupational therapists can provide assessments and training in a variety of work, leisure, and daily occupations (Eismann et al., 2017)

Research also shows, through the use of the lifespan developmental frame of reference, that occupational therapists can assist clients with transitional tasks using knowledge of typical stages of adulthood and the stressful life tasks that follow (Levinson, 1978). The lifespan development framework guides occupational therapists to help the client establish age-appropriate occupations within continued life roles, as well as helping them to adapt to the changes brought on across the lifespan development continuum (Levinson, 1978).

\section{Barriers to Occupational Therapists' Participation in Transition Services}

Occupational therapists can contribute to transition planning with their expertise in daily living skills, work, leisure, and community participation (Kardos \& White, 2005). Research has shown that occupational therapists are not addressing secondary transition services in schools as much as they could be (Kardos \& White, 2005). Barriers found throughout literature include:

- Lack of funding, interagency planning, and parent participation (Spencer et al., 2003)

- May be seen as a higher cost provider, impacting utilization (Kardos \& White, 2005)

- Lack of understanding of an occupational therapists' role and potential benefits in transition programs (Kardos \& White, 2005) 


\section{Literature Review Conclusion}

The literature has shown the difficulties that high-risk youth have with the transition from high school to college. Research has examined several aspects of transition programs that may be useful in helping ease this transition. The use of occupational therapists has been overlooked, however, research has shown the benefits that occupational therapy could provide in these programs. Following the guidelines of the lifespan developmental frame as well as PEOP can help create a transition program that could help many high-risk students with this difficult transition.

\section{Chapter 3: Project Description}

This capstone project aims to develop a life skills transition program to help support the transition from high school to college for high risk youth. Research has shown that high risk youth, such as those with disabilities, have a difficult time with this life transition. Occupational therapists can contribute to a more successful transition by helping these individuals gain and integrate the life skills needed for college. Although research has shown the benefits of occupational therapist's participation in transition programs, their participation is limited (Eismann et al., 2017). Therefore, it is important to create a transition program, with guidance of occupational therapists, in order to prepare students for this period. The main outcome objectives of this program include assessing the students' needs in the area of life skills and developing/implementing a life skills program to help support the transition from high school to college.

\section{Design}

According to the PEOP model, it is important for the client to identify the most important occupation performance issues (Baum \& Christiansen, 2005). Following this step of the model, a 
needs assessment will be used to find the life skills areas the students would most like to focus on for the program. The needs assessment will follow the top-down approach of the PEOP model, that begins with the practitioner assessing the client's perception of problems within occupational performance (Baum \& Christiansen, 2005). Another key principle that the PEOP model emphasizes is human agency, which is that individuals have an innate drive to demonstrate mastery within their environment using a variety of skills (Baum \& Christiansen, 2005). This program is designed to assist students in gaining knowledge on life skills that they will need to use in order to master the transition from high school to college.

This project is also designed based on research from a variety of effective life skills programs. Research shows that how life skills programs are structured and implemented can have a large impact on long-term program quality, therefore, it will be important to deliver the program systematically to have lasting impacts on the participants (Holt et al., 2008). This program will integrate a variety of teaching methods, which has been shown in research to ensure participant involvement and internalization of information (Nasheeda et. al, 2018). Research has also shown that there are deficiencies in transfer skills when a variety of approaches such as modeling, imitation, and reinforcement were not used (Nasheeda et. al, 2018).

To ensure variety of teaching methods in this program, lessons were taught virtually based on the life skill topics selected, and opportunities to apply these skills through community activities will be available in the future (due to Covid-19). PowerPoint presentations were distributed to ensure students have resources to look back on when needed. Active discussion and participation were also a large part of the class in order to keep the students engaged. 


\section{Setting}

This program was developed and implemented at the Winston School located in Del Mar, CA. Winston School is an independent day school for youth grades 6-12 whose needs were not being met in the traditional school setting. Many of these students have been diagnosed with learning disabilities or other health impairments that may impact their ability to learn. The Winston School focuses on individualizing the curriculum to the student to help them be successful.

\section{College and Career Readiness Class (CCRC)}

The college and career readiness class (CCRC) was initially developed by a former occupational therapy doctoral (OTD) student and was designed to cover three major areas important for transition: financial literacy, college and career preparation, and life skills. Each area of transition was addressed by a different OTD student, leading to a comprehensive program preparing students at Winston for the transition out of high school.

\section{Participants}

The participants of the CCRC class consisted of $11^{\text {th }}$ and $12^{\text {th }}$ graders who signed up for the class as an elective. The 8 students in the CCRC class had wide range of abilities, with some students requiring more support and guidance than others.

\section{Curriculum Development}

Needs Assessment. The needs assessment included a life skills student interest survey and a life skills staff interest survey. The purpose of the needs assessment was to gather information on life skills that students were interested in learning more about, as well as areas that staff members found a need for with their students. 
Life Skills Student Interest Survey. Students in the CCRC participated in a life skills interest survey in order to gain information on which topics students would like to focus on. This information helped tailor the life skills portion of the CCRC the students' needs. The results of the survey are outlined in Figure 1 below. Five students $(n=5)$ total participated in the life skills interest survey. Students were asked to choose six areas of life skills they would like to focus on from the following list: self-care, sleep, conflict resolution, home management/independent living, food \& nutrition, health and medication management, community mapping, time management, positive recreation \& leisure, and stress management. The results of the survey displayed the top three life skills topics of interest being self-care, food and nutrition, and time management. These topics were chosen as part of the life skills unit taught in the CCRC. The results of the survey also showed an equal amount of interest (3 votes) for the following topics: sleep, conflict resolution, home management/independent living, health/medication management, positive recreation and leisure, and stress management. The students were also asked to identify other life skills areas of interest in a free response question, outlined in Table 1 below. The remaining topics for the CCRC life skills unit were decided based on the life skills staff survey described in the following section. 


\section{Figure 1}

Life Skills Student Interest Survey Results

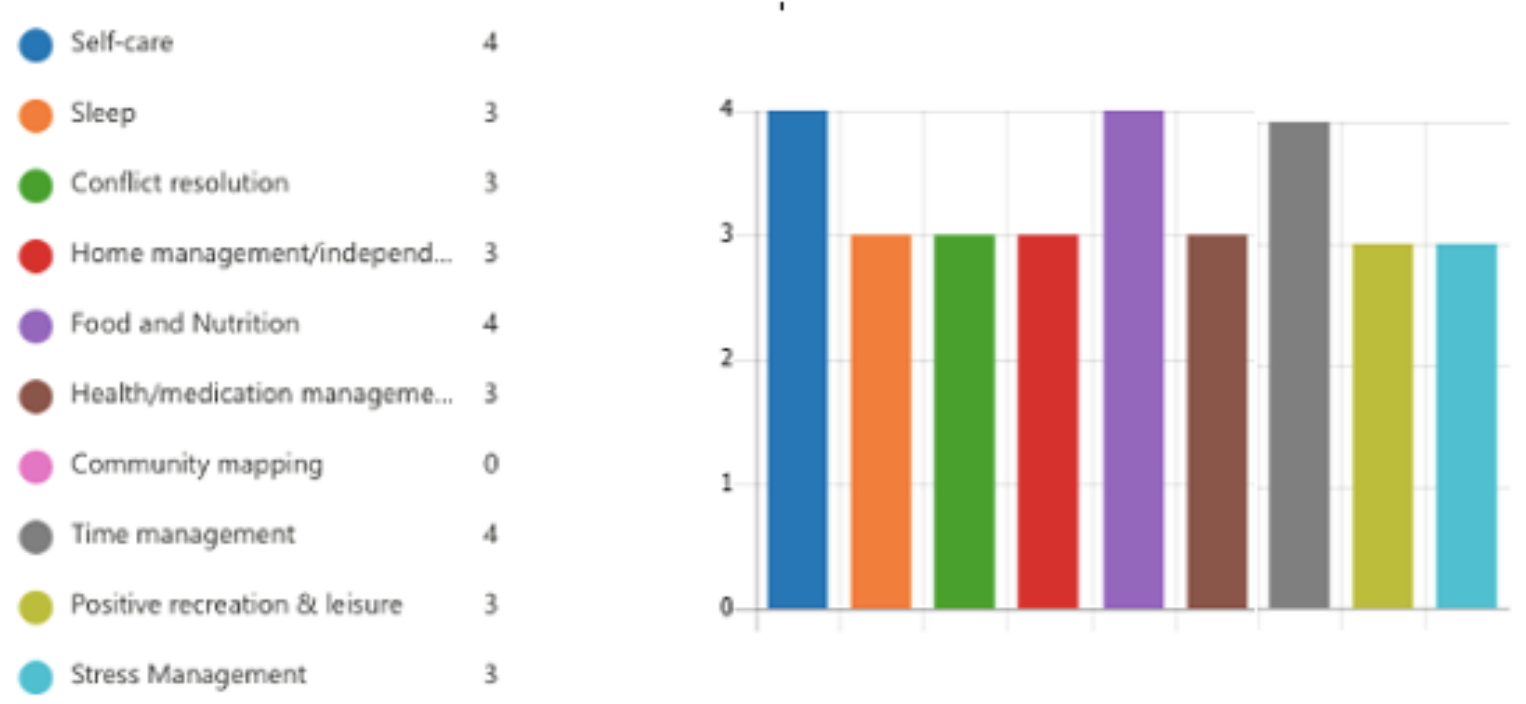

\section{Table 1}

Sample Life Skills Student Interest Survey Qualitative Responses

\section{Question}

Are there any other areas of life skills you would like to learn about?

\section{Response}

- I would like to learn about living areas and the process of moving out

- Staying on top of things

Note. Student verbatim responses documented with original grammar, spelling, and punctuation

Life Skills Staff Interest Survey. A survey was sent out to the staff at Winston to gather information on life skills areas their students demonstrate the most need in (see appendix B). The survey was sent out to staff members via email and consisted of the same questions as the student interest survey. The results of the survey are outlined in figure 2 below. A total of seventeen $(n=17)$ staff members, teaching a variety of subjects and grade levels, participated in 
the life skills staff survey. The top three life skills topics identified by staff members included stress management (16 votes), time management (15 votes), and conflict resolution (12 votes). Staff members were also asked an open-ended question to gather information on additional life skills areas of importance for their students. Qualitative results were outlined below in Table 2. Additional life skills topics developed from qualitative responses included interpersonal relationships, professional emails, and public speaking.

\section{Figure 2}

\section{Life Skills Staff Interest Survey Results}

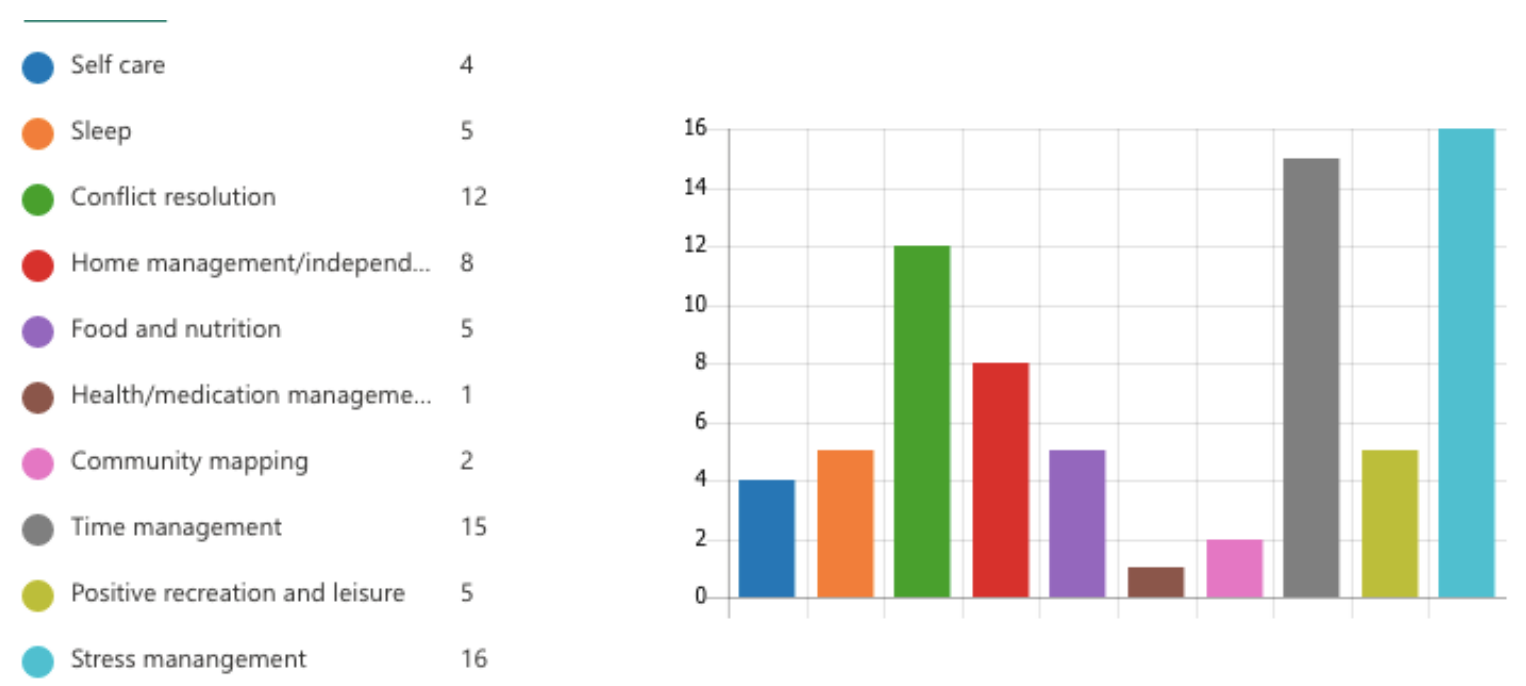

Table 2

Sample Life Skills Staff Interest Survey Qualitative Responses

\section{Question}

Are there any other areas of life skills not listed above that you see your students having difficulty with?

\section{Response}

- Kind of like time management, but schedule organization, making lists of things they need to do and prioritizing and maybe setting phone reminders.

- Relationship management (with peers, parents, teachers, bosses etc.)

- Financial awareness

- Money management/budget 
- With regards to sleep, I think sleep hygiene is the issue with a lot of these kids, not just knowledge of why sleep is important. They would benefit from learning why using their computer/phone right before bed lessens the quality of their sleep; to keep regular-ish hours on the weekends; to do things consistently before bed; etc.

- Money management ( may be part of independence), job etiquette, how to be a friend (these may also be included in some already checked off)

- Organization and planning - executive functioning (more than time management)

- Social/Friendship-building skills

- Appropriate conversation topics or responses might be an interesting one! I think in general high school students can be blunt and come off rude without knowing!

- Communication: talking on the phone with someone versus texting, professionalism and appropriateness

- A few have difficulty extending their social groups. Some do not have any.

- Self-advocacy (even knowing the meaning of this word for some!)

- Managing anxiety/frustration/self-advocacy

Note. Staff members verbatim responses documented with original grammar, spelling, and punctuation.

Content Development. Content for the life skills unit of the CCRC was continuously developed throughout the 14 week program at the Winston School. Lesson plans and occupationbased class activities/assignments were created for the following life skills topics: community mapping, conflict resolution, driving, food \& nutrition, health/medication management, independent living/home management, interpersonal relationships, public speaking, self-care, sleep, stress management, professional emails, and time management. PowerPoint presentations were developed for each life skills topic and focused on introducing key information and strategies for success. For example, students learned strategies for conflict resolution, making effective presentations, maintaining the home, and managing time and stress. In addition to PowerPoint presentations, occupation-based class activities as well as assignments were developed as an outcome measure to assess the students understanding and knowledge of the 
topic. Sample completed assignments as well as detailed directions were included to give students more support in the virtual setting. Guided by the PEOP model, class activities and assignments emphasized the reflection and practice of life skills in the students' everyday life. For example, a self-care bingo assignment required students to reflect on potential self-care activities important to them under each of the three areas of health (mental, emotional, physical). Another assignment that required reflection included a sleep journal in which students tracked their sleep and reflected on any habits that may have affected quality and quantity of sleep. Many assignments developed for the life skills unit allowed students to practice applying the life skill. For example, students were able to practice applying their knowledge on food labels from the PowerPoint presentation to an interactive food label assignment. By taking into consideration all aspects of the PEOP model (person, environment, and occupation), class activities and assignments were created to best support the students learning.

\section{Procedures and Timeline}

Due to Covid-19, life skill lesson plans were implemented virtually through the CCRC. The timeline of implementation of the life skills unit in the CCRC is outlined in Table 3. Students were given a detailed schedule for the week, including times for zoom meetings as well as assignments and due dates. Lessons were taught virtually, through PowerPoint presentation, allowing the students to refer back when needed. Occupation-based assignments corresponding to each life skill topics were given to help solidify the information. The CCRC was held twice a week (45-minute sessions), with Mondays being check in days, and Wednesdays being lecture days. Two life skills topics were covered per week, one via Zoom, and one posted on the class page for independent review. The PowerPoint presentations posted on the class page for independent review were voiced over by the occupational therapy doctorate student to enhance 
the learning experience. Seven topics were addressed in the CCRC due to time constraints however, curriculum was developed for the additional life skills topics and are available to staff at Winston.

\section{Table 3}

Timeline of Life Skills Unit in CCRC

Week 1: May $11^{\text {th }}-$ May $15^{\text {th }}$

Date

Monday May $11^{\text {th }}$

\section{Lesson Topic}

-Class check in -Life Skills Interest Survey (see Appendix A)

Week 2: May $18^{\text {th- }}$ May $22^{\text {nd }}$

Monday May $18^{\text {th }} \quad-$ Class check in $\quad$ None

Wednesday May 20 ${ }^{\text {th }} \quad$-Life Skills Pre-Survey (see Appendix C)

-Life Skills Introduction -Self-Care (see Appendix F)

Friday May $22^{\text {nd }}$ - Sleep (see Appendix G)

\section{Outcome Measure} (Assignment/Class Activities) None

\section{Complete Self-Care Bingo} assignment located in Unified Classroom

Complete the Sleep Diary

Reflection assignment located in Unified Classroom

Week 3: May $25^{\text {th }}$-May $29^{\text {th }}$

Wednesday May $27^{\text {th }} \quad$ - Conflict Resolution (see Appendix $\mathrm{H}$ )

Friday May $29^{\text {th }}$

- Food \& Nutrition (see Appendix I)
Complete the Approached to Conflict located in Unified Classroom

Complete the Nutrition Facts Label assignment located in Unified Classroom

Week 4: June $1^{\text {st }}-J u n e 5^{\text {th }}$ 


\begin{tabular}{|c|c|c|}
\hline Monday June $1^{\text {st }}$ & -Finish Incomplete Assignments & $\begin{array}{l}\text { Finish Nutrition Facts Label } \\
\text { Assignment } \\
\text { Work on other incomplete } \\
\text { assignments }\end{array}$ \\
\hline Wednesday June $3^{\text {rd }}$ & $\begin{array}{l}\text { - Time and Stress Management } \\
\text { (see Appendix J \& K) }\end{array}$ & $\begin{array}{l}\text { Complete Prioritizing } \\
\text { assignment located in Unified } \\
\text { Classroom }\end{array}$ \\
\hline Friday June $5^{\text {th }}$ & $\begin{array}{l}\text { - Independent Living and Home } \\
\text { Management (see Appendix L) }\end{array}$ & $\begin{array}{l}\text { Complete the Home } \\
\text { Management assignment located } \\
\text { in Unified Classroom }\end{array}$ \\
\hline \multicolumn{3}{|c|}{ Week 5: June $8^{\text {th }}-$ June $12^{\text {th }}$} \\
\hline Monday June $8^{\text {th }}$ & -Class check in & None \\
\hline Wednesday June $10^{\text {th }}$ & $\begin{array}{l}\text {-Life Skills Post-Survey (see } \\
\text { Appendix D) } \\
\text {-Work on missing/incomplete } \\
\text { assignments }\end{array}$ & \\
\hline
\end{tabular}

\section{Summer Health Class}

Life skill lesson plans were integrated into the summer health class curriculum with the collaboration of the health teacher and the OTD student. The main objectives of the health class were to give the students information and tools to help maintain good health.

\section{Participants}

The participants of the health class included students going into $9^{\text {th }}, 10^{\text {th }}$, and $11^{\text {th }}$ grade and enrolled in Winston summer school. Similar to the CCRC, the eleven students in the health class had a large range of learning abilities. Therefore, some students required more support than others to help clarify the information. 


\section{Curriculum Development}

The curriculum for the health class was adapted from material in the CCRC. Life skills lesson plans were created using information from CCRC, as well as information from the Lifetime Health textbook. The life skills topics covered included: self-care, food \& nutrition, time management, and stress management. A variety of skills were covered such as ways to maintain mental, emotional, and physical health, choosing healthy meals and snacks, and strategies to better manage time and stress. Lessons were taught virtually using PowerPoint presentations to allow students to refer back for more information. Interactive tools such as Mentimeter, YouTube videos, and jeopardy were used during the health class to increase active learning and keep students more engaged. Active learning has been shown to provide the following benefits: more involvement than passive learning, students are more engaged in activities, student motivation is increased, students can receive immediate feedback, and students may engage in higher-order thinking such as evaluation, analysis, synthesis (Michel et al., 2009). Due to the benefits of active learning, interactive tools were an important component the life skill lessons.

\section{Procedures and Timeline}

The implementation timeline of life skill lessons in the summer health class is outlined in Table 4 below. Lessons were taught virtually, through PowerPoint presentation and occupationbased classwork corresponding to each life skill topics were given. The summer health class was held 5 days a week (Monday-Friday) in 30-minute sessions. The format of the summer health class different significantly from the CCRC. Mondays and Wednesdays were used for introduction of material through PowerPoint presentations while Tuesdays and Wednesdays were used to help students through assigned occupation-based classwork. This class format allowed 
for students to apply information learned from the previous day and receive support when needed. Fridays were used to discuss and reflect on material through either an assignment, or a jeopardy game corresponding to topics taught that week. By implementing life skill lessons into different subjects, such as the health class, students will be better prepared to apply these skills to a variety of situations.

\section{Table 4}

Timeline of Health Class Throughout the Capstone Experience

Introduction Week

\begin{tabular}{|c|c|c|c|c|}
\hline June 22 & June 23 & June 24 & June 25 & June 26 \\
\hline Monday & Tuesday & Wednesday & Thursday & Friday \\
\hline $\begin{array}{l}\text { No } \\
\text { School }\end{array}$ & $\begin{array}{l}\text { Summer } \\
\text { School Staff } \\
\text { Meeting and } \\
\text { Planning Day }\end{array}$ & $\begin{array}{l}\text { First Day } \\
\text { Expectations } \\
\text { Grading } \\
\text { Schedule } \\
\text { Digital Site } \\
\text { log in }\end{array}$ & $\begin{array}{l}\text { Break out groups } \\
\text { Set up expectations } \\
\text { Give task for breakout } \\
\text { groups - talk about } \\
\text { highs and lows about } \\
\text { health } \\
\text { "What does health } \\
\text { mean?" } \\
\text { Come back together }\end{array}$ & $\begin{array}{l}\text { Small group break out } \\
\text { discussions, come } \\
\text { together for class } \\
\text { discussion on definition } \\
\text { of health }\end{array}$ \\
\hline
\end{tabular}

General Health \& Self-Care

\begin{tabular}{lllll}
\hline $\begin{array}{l}\text { June } 29 \\
\text { Monday }\end{array}$ & $\begin{array}{l}\text { June } 30 \\
\text { Tuesday }\end{array}$ & $\begin{array}{l}\text { July 1 } \\
\text { Wednesday }\end{array}$ & $\begin{array}{l}\text { July 2 } \\
\text { Thursday }\end{array}$ & $\begin{array}{l}\text { July } 3 \\
\text { Friday }\end{array}$ \\
$\begin{array}{l}\text { General Health } \\
\text { PowerPoint }\end{array}$ & $\begin{array}{l}\text { Independent } \\
\text { assignment }\end{array}$ & $\begin{array}{l}\text { Self-Care } \\
\text { PowerPoint (see } \\
\text { Appendix M) }\end{array}$ & $\begin{array}{l}\text { Independent } \\
\text { assignment }\end{array}$ & $\begin{array}{l}\text { No } \\
\text { School }\end{array}$ \\
\hline
\end{tabular}

Anatomy \& Physiology

\begin{tabular}{lllll}
\hline $\begin{array}{l}\text { July } 6 \\
\text { Monday }\end{array}$ & $\begin{array}{l}\text { July } 7 \\
\text { Tuesday }\end{array}$ & $\begin{array}{l}\text { July } 8 \\
\text { Wednesday }\end{array}$ & $\begin{array}{l}\text { July } 9 \\
\text { Thursday }\end{array}$ & $\begin{array}{l}\text { July } 10 \\
\text { Friday }\end{array}$ \\
$\begin{array}{l}\text { Human Body } \\
\text { Presentation }\end{array}$ & $\begin{array}{l}\text { Organ Systems } \\
\text { Edpuzzle }\end{array}$ & $\begin{array}{l}\text { Fitness Presentation } \\
\text { (Taught by health } \\
\text { teacher John } \\
\text { Webber) }\end{array}$ & $\begin{array}{ll}\text { FIIT Practice } \\
\text { Anatomy \& }\end{array}$ & $\begin{array}{l}\text { Physiology } \\
\text { Bingo Jeopardy }\end{array}$ \\
\end{tabular}


(Taught by

health teacher

John Webber)

Exercise \& Nutrition

\begin{tabular}{|c|c|c|c|c|}
\hline July 13 & July 14 & July 15 & July 16 & July 17 \\
\hline Monday & Tuesday & Wednesday & Thursday & Friday \\
\hline Food \& & Interactive & What Makes Up & Food Label & Developing a \\
\hline Nutrition & Food Label & Food Presentation & Practice Work & Balanced Meal \\
\hline Presentation & Class & (Taught by health & & Assignment \\
\hline (see Appendix & Assignment & teacher John & & \\
\hline & & Webber) & & \\
\hline
\end{tabular}

Time \& Stress Management

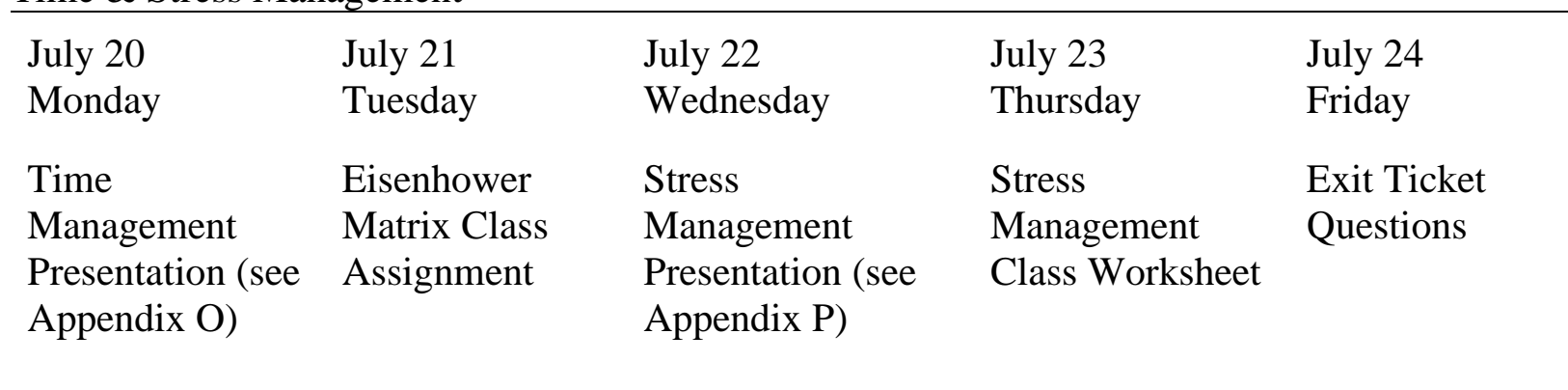

Diseases \& Disorders

\begin{tabular}{|c|c|c|c|c|}
\hline July 27 & July 28 & July 29 & July 30 & July 31 \\
\hline Monday & Tuesday & Wednesday & Thursday & Friday \\
\hline Diseases & Student & Disorders and & Student Disorder & Student \\
\hline Presentation & Disease & Genetic Conditions & Research & Presentations \\
\hline $\begin{array}{l}\text { (Taught by health } \\
\text { teacher John }\end{array}$ & Research & $\begin{array}{l}\text { (Taught by health } \\
\text { teacher John }\end{array}$ & & \\
\hline Webber) & & Webber) & & \\
\hline
\end{tabular}

Self-Reflection

\begin{tabular}{lllll}
\hline $\begin{array}{l}\text { August } 3 \\
\text { Monday }\end{array}$ & $\begin{array}{l}\text { August } 4 \\
\text { Tuesday }\end{array}$ & $\begin{array}{l}\text { August 5 } \\
\text { Wednesday }\end{array}$ & $\begin{array}{l}\text { August 6 } \\
\text { Thursday }\end{array}$ & $\begin{array}{l}\text { August 7 } \\
\text { Friday }\end{array}$ \\
\hline
\end{tabular}




Self-Reflection Make-up Work Health Jeopardy
Project
Health Class
Survey

\section{Future Plans for Evaluation}

Effectiveness of the life skills program was measured through occupation-based assignments as well as pre- and post- survey results. Future plans for evaluation may include the development of a survey to measure efficacy in life skills. A pre- and post- survey should be developed and guided by the self-efficacy scale, in order to measure the students' change in level of confidence with applying certain life skills. The self- efficacy scale is used to assess optimistic self-beliefs to cope with a variety of difficult demands in life (Romppel et al., 2013). This scale would be a useful tool to help guide the creation of the life skills survey.

Future evaluation of the effectiveness of this program should also include formal assessments given by the occupational therapist at Winston School. Formal assessments will allow for standardized results to help assess the effectiveness of the life skills program. An assessment that could help evaluate this programs' effectiveness includes the Life Skills Inventory Independent-Living Skills Assessment Tool, which is used to asses where students are in the process of living independently ("Life Skills Inventory", n.d.). This assessment covers many categories of life skills including money management, food management, housekeeping, health and interpersonal skills (Vogelsberg, 1980). The style of this assessment is a checklist format (see Appendix Q) in which the student can assist another person in evaluation of themselves. This assessment could help evaluate if the students are benefiting from the transition program and if any adjustments are necessary. 


\section{Project Description Conclusion}

This project aimed to create a life skills transition program to help prepare high school students at Winston School for the transition to college. This project will be guided by the lifespan developmental frame of reference, which emphasizes the importance of transition periods in the development of youth. This project is also guided by the PEOP model, which focuses on the various factors that can affect an individual's performance. Once this program is developed, implemented, and evaluated, it is envisioned that the program will continue being taught by the faculty and occupational therapist at Winston. It is also envisioned that the program will be implemented in other schools in the San Diego area. A large amount of youth display difficulties with this transition from high school to postsecondary education. Therefore, it is important to implement transition programs in all high schools in order to ease this transition period for young individuals.

\section{Chapter 4: Evaluation of Life Skills Program}

\section{CCRC Life Skills Pre- and Post- Survey Quantitative Data}

Based on the student interest survey as well as the staff survey, seven life skills topics (self-care, sleep, conflict resolution, food \& nutrition, stress management, time management, and home management/independent living) were chosen for the CCRC. Students in the CCRC participated in a life skills pre- and post- surveys to assess the effectiveness of the life skills program (see Appendix C \& Appendix D). The quantitative results of the pre- and post-life skills survey are outlined below (see Figure 3). Six participants completed the pre-survey and five participants completed the post-survey A 5-point Likert scale, with 1 being strongly disagree and 5 being strongly agree, was used to assess the students' knowledge of various life skills topics. The questions started with the statement "I know how to" or "I am able to" and were 
completed based on the life skill topic. For example, students were asked to rate the statement "I know how to choose healthy meals and snacks" to assess knowledge for the food \& nutrition topic. Questions related to the following seven life skills topics taught in class: self-care (how to manage mental health, emotional health, and physical health), sleep, time management, stress management. The life skills post-survey contained the same Likert scale questions as the presurvey in order to gain insight on the effectiveness of the life skills unit. Students average ratings increased in 7 of the 9 questions: managing mental health $(+20 \%)$, managing physical health $(+14.6 \%)$, maintaining a good sleep routine $(+2 \%)$, time management $(+10 \%)$, stress management $(+6 \%)$, conflict resolution $(+8.6 \%)$, and choosing healthy meals and snacks $(5.4 \%)$. Two areas that students' average ratings went down from the pre- to the post-survey were managing emotional health $(-5.4 \%)$ and maintaining living space $(-23 \%)$.

\section{Figure 3}

\section{Likert-Scale Result Averages for Life Skill Survey Questions}

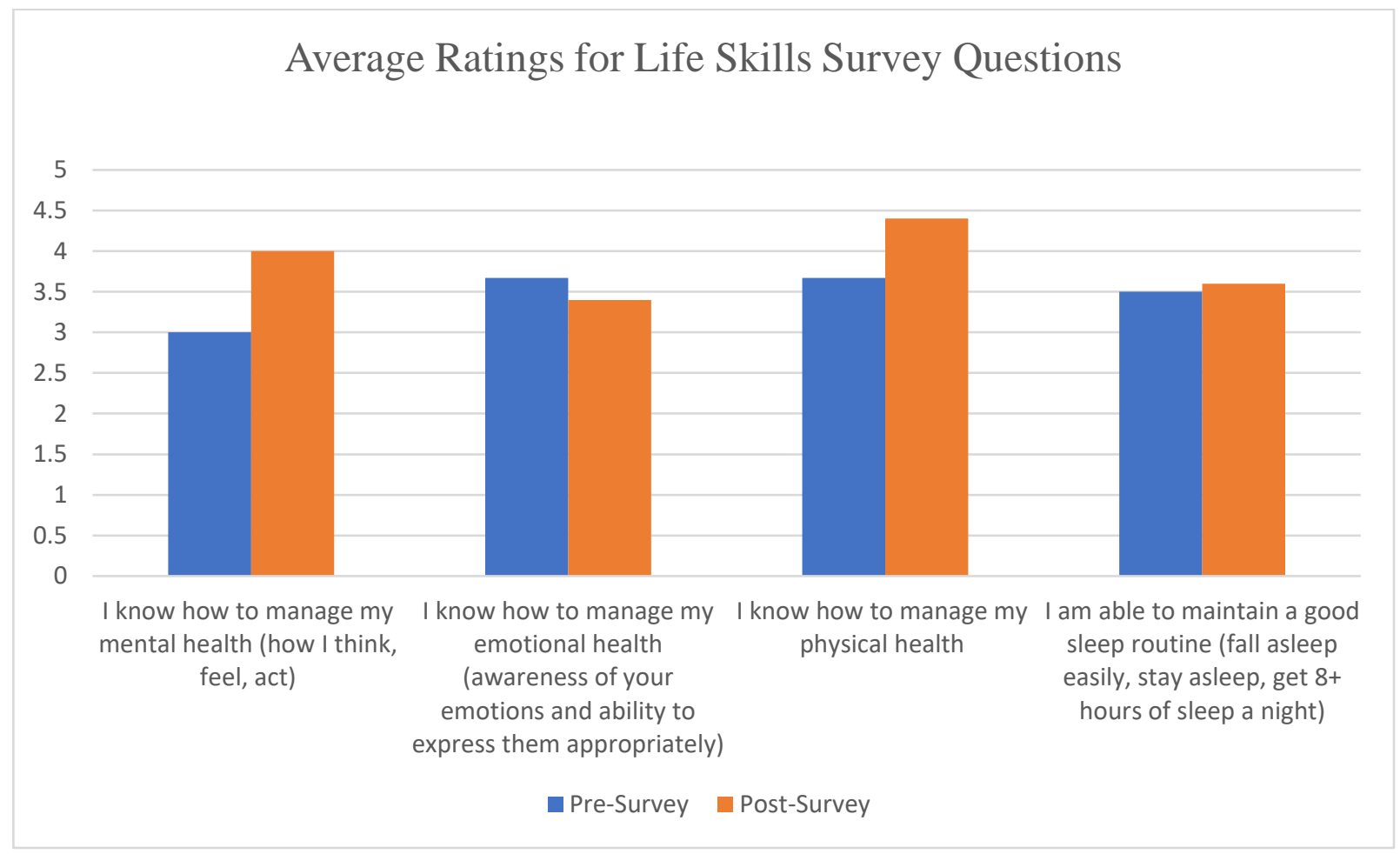




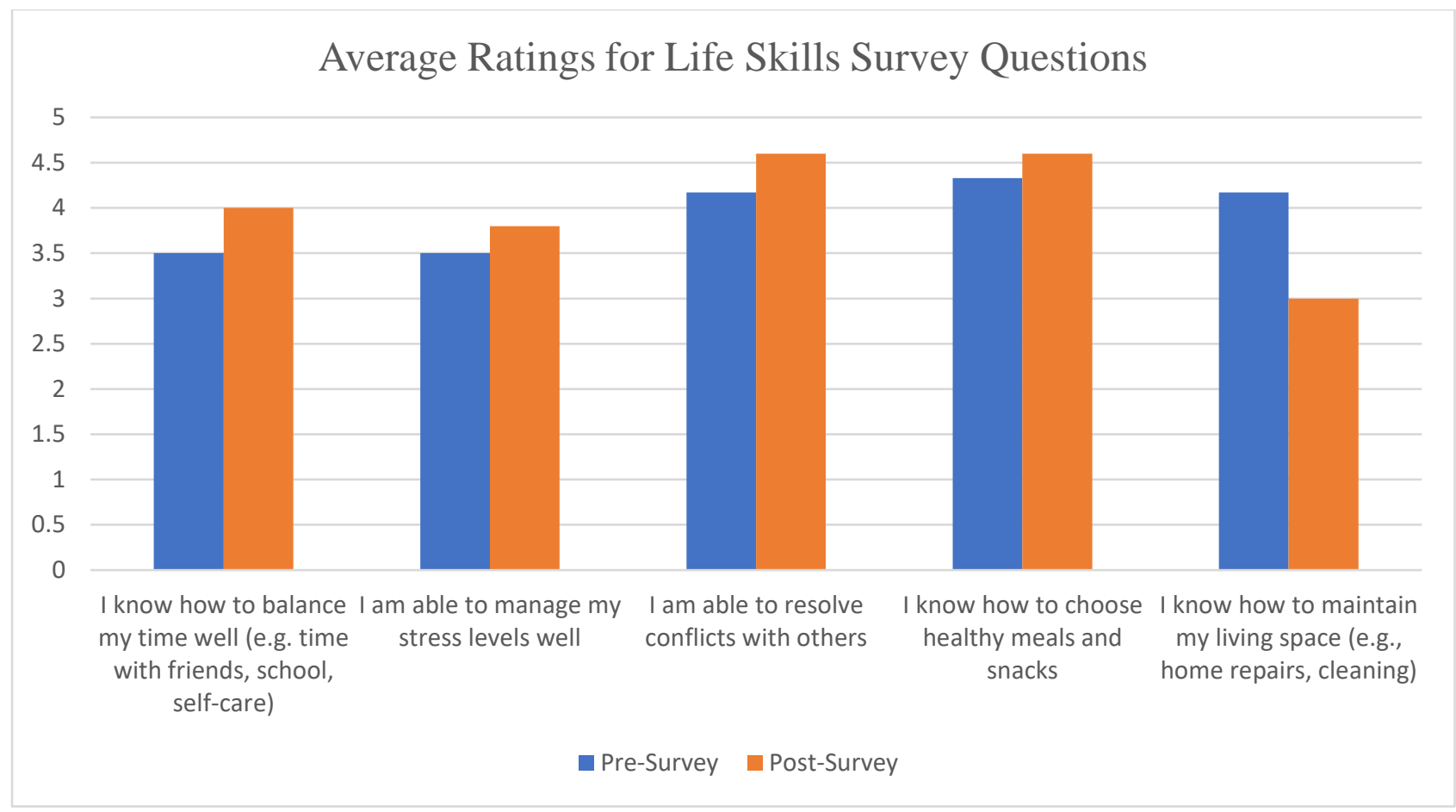

\section{CCRC Life Skills Pre- and Post- Survey Qualitative Data}

The life skills pre- and post- survey also included open-ended qualitative questions to gather more in depth insight from students. Responses can be found in Table 5 below. Openended questions were used to gain information on life skill areas the students were familiar with and which areas they felt confident in/struggled with. Students were asked to name examples of life skills needed post- high school, and to name which life skills they felt confident with as well as which ones they struggled with. Six students participated in the pre-survey and five students participated in the post-survey. Due to the small number of participants, the qualitative survey responses are difficult to generalize to the entire population at Winston. However, the responses give us more information on the students' knowledge of the importance of life skills, as well as the effectiveness of the program. Students were asked if they felt more confident after the life skills unit and all five students displayed positive responses. 
Table 5

Life Skills Pre-Survey Qualitative Responses

\section{Question}

What are some examples of life skills you may need after high school?

What life skills do you feel confident with?

What are some examples of life skills you have difficulties with

What strategies do you use to manage your stress?

What strategies do you use to resolve conflicts with others?

What is a goal you have for yourself related to life skills?

\section{Response}

- Independence

- Living somewhere less, cooking, driving

- Saving money, doing duties such as going to jury duty, paying for tickets incase i get any, Learning how to do taxes, and living life to the fullest

- Communication, responsibility, respect

- I will need food and some sleep

- Being social??? im pretty independant im good at saving

- I feel like I can wake up early in the morning and not staying up late

- I feel confident with time and money management

- Communication, understanding

- I feel confident with saving food

- Cooking

- I can eat food

- Budgeting can be difficult

- Getting things done on time

- Driving

- Stress with financial stability

- Getting chores or duties done

- Grounding techniques

- Walk around

- I just deep breath and go to theme parks and ride roller coasters

- Writing, talking to others

- Deep breathing and positive self talk

- I can take a break and get some air

- Verbal communication

- Get to know them

- I just say im sorry for what i have done and walk away

- Communication, comprise

- I would bring up the issue at hand and address my point and listen to theirs

- I can do something else

- Rich and famous and to marry rich

- To learn everything i can

- My goal is to survive while being alone

- I want to work on my mental health

- To be successful with most of my life goals 
- I can be relax

Note. Student verbatim responses documented with original grammar, spelling, and punctuation

\section{Table 6}

Life Skills Post-Survey Qualitative Responses

\section{Question}

What strategies can you use to resolve conflicts with others?

Why do you think it is important to learn about life skills?

Do you feel more confident after the life skills unit? Why or why not?

\section{Responses}

- I can say im sorry for what I have done. I will take blame.

- I can take a break on the computer.

- Figure out a solution and problem solve what is wrong

- Forgive, listen carefully and talk together

- Communication

- I think this so that way in case we need to learn them we can improve on them

- I can relax and do my homework

- To be prepared and ready for your future

- I think it help with your every day life

- If you don't have knowledge about life skills, $\mathrm{i}$ mean its pretty self explanitory,

- I kind of do feel more confident because I learned about how to save money, sleep schedule, goals, and etc.

- I can do it

- I do feel more confident know about interviews and how to balance my money

- Yes because i learn many more thing that i didn't know.

- Yes, cuz i got more info on it queen

Note. Student verbatim responses documented with original grammar, spelling, and punctuation

\section{Health Class Survey Quantitative Data}

The health class was given a survey in order to gain feedback on the life skills lessons taught in the class (see Appendix E) Quantitative data using a 5-point Likert scale was gathered for each of the four life skills topics (self-care, food \& nutrition, time management, and stress management). Students were asked how knowledgeable they felt about each life skills topic after 
taking the health class. Students average ratings are displayed in figure 4 below. The results display a high rating in all four life skills topics: self-care (4), food \& nutrition (4), time management (4.25), and stress management (4.25). Although the results of the survey showed a high rating, there was a small sample size (4 participants) and no pre-survey data to make a comparison. Therefore, the quantitative responses cannot be generalized to the whole population at Winston.

The structure of summer health class varied greatly from the CCRC during the school year. Lectures were given on Monday/Wednesdays and occupation-based class assignments corresponding to each topic were given on Tuesday/Thursdays. This format allowed the students to process information and apply it to the class assignments with support when needed. Although the grade level varied between the 2 classes, the majority of the material presented was the same. The health class surveys displayed higher average student ratings on all 4 life skills topics compared to the CCRC. This may be due to the difference in structure of the health class, allowing more time for guidance and support through assignments. By allowing for class time to work on assignments, students were able to ask questions and better apply the material taught the previous day. 


\section{Figure 4}

Likert-Scale Result Averages for Health Survey Questions

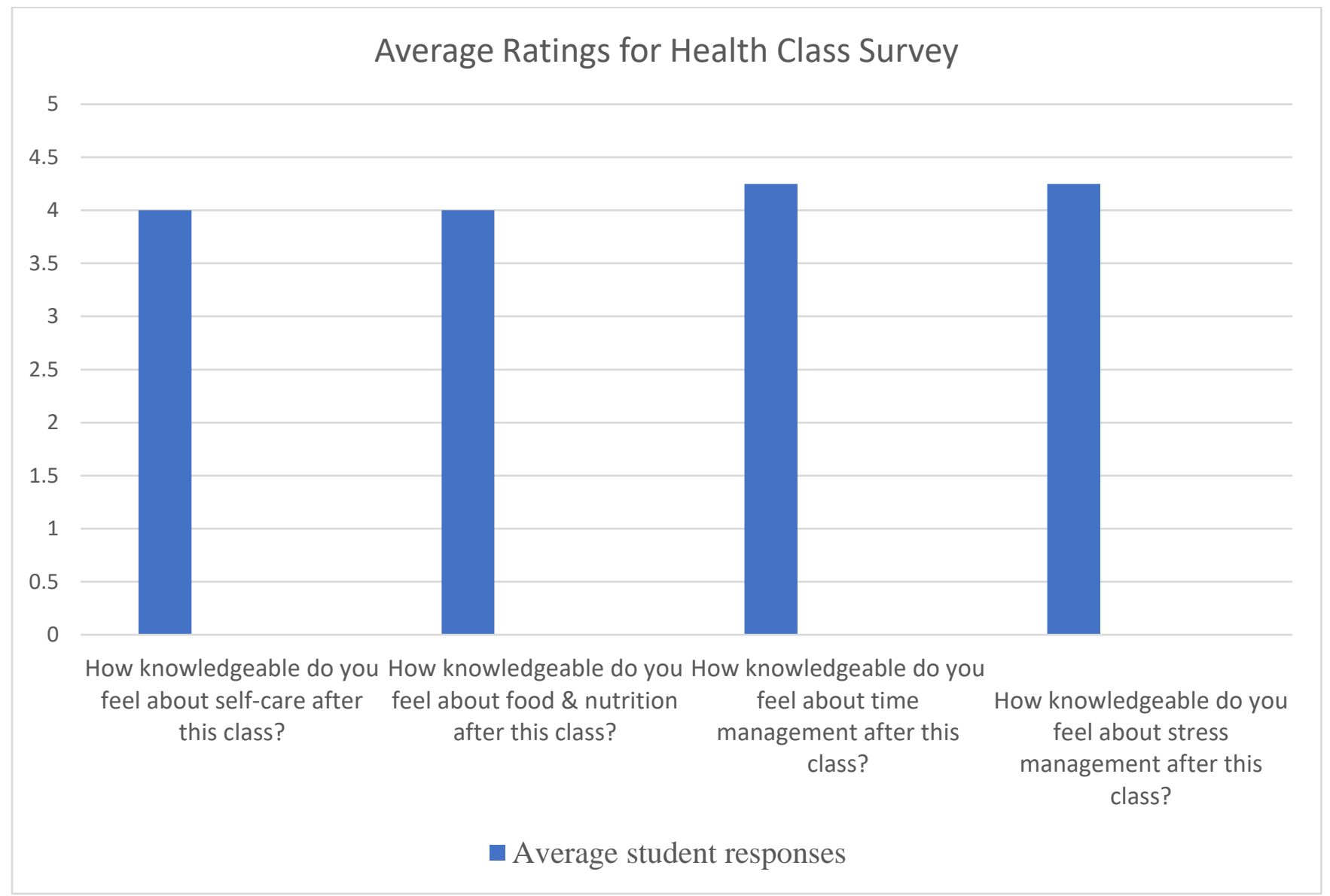

\section{Health Class Survey Qualitative Data}

The health class survey included qualitative questions, to gather information on the students understanding of the main points in each life skills lesson. Student responses are displayed below (see Table 7). The small number of participants (4) makes the qualitative responses hard to generalize to the population at Winston. However, the responses give us a greater knowledge of what the students retained from the life skills lessons. Overall, student responses showed a great amount of knowledge gained from the life skill topics presented. 


\section{Table 7}

Life Skills Pre-Survey Qualitative Responses

\section{Question}

What did you learn about selfcare in this class?

What did you learn about food \& nutrition in this class?

What did you learn about time management in this class?

What did you learn about stress management in this class?

\section{Response}

- To put face lotion on my face and use hand lotion all the time

- I learned that taking showers is very important

- More about different techniques to help with my self-care and different strategies to for time management

- Stuff I already knew like to not be too hard on yourself

- Learn how to read nutrition labels

- I learned that different foods have different nutrition values

- Well the lot about different foods that help with your nutrition and give you a more balanced diet I also learned a lot about foods other than read that provide protein stuff that your body needs

- Stuff I already knew like to not be too eat health and in moderation, and the nutritional facts say per serving in fine print

- I learned that I need to manage my day better

- I learned that time management help you manage your time

- Learn about the difference in energy level throughout the week and had to prioritize different assignments in a different coping mothods your help with stress management which can improve your time is

- Stuff I already knew like to manage your time right

- I learn how to do breathing exercises when I'm stressed

- I learned that you need to control your stress

- I different coping skills that help with time management Including things like putting your phone away when you're working

- That you can take breaks and try to get your mind off something If you are overstressed

Note. Student verbatim responses documented with original grammar, spelling, and punctuation 


\section{Chapter 5: Discussion \& Conclusion}

\section{Discussion}

The strong connection between life skills and successful transition has called for an increase of integration of life skills instruction into curriculum (Bouck, 2010). Research has shown life skills curriculum is connected with a variety of student outcomes including functional academics, community access, social/relationships, transportation, and independent living (Bouck, 2010). In order to promote successful student outcomes, it was essential to create a life skills component for the CCRC. Taking into consideration the students learning abilities as well as the virtual environment, life skills lessons were developed and implemented in the CCRC and health classes.

Each life skills topic was covered in detail through PowerPoint presentations, occupationbased class activities, and assignments. Through the life skills pre- and post- survey, an increase in knowledge was shown in the following areas: managing mental health, managing physical health, maintaining a good sleep routine, time management, stress management, conflict resolution, and choosing healthy meals and snacks. The two areas where a decrease in knowledge was reported included managing emotional health and maintain living space. The exact cause of the decrease is unknown, however, there are some factors that could have had an effect. Students' may have lacked an understanding of the life skill and what it entailed, overestimating their knowledge of the topic. Adolescents with disabilities have been shown to hold unexpectedly optimistic beliefs about their capabilities for various academic tasks (Klassen, 2002, 2007). After gaining a greater understanding of the depth of the life skill, students may have lowered their rating to be more representative of their level of knowledge. Students may have also had some difficulties with the transition to online learning. Many students have been 
shown to have a difficult time with the absence of in-person support to help explain instructions and follow up with help when needed (Gilbert, 2015). Students can experience a large learning curve when asking for help in the virtual form, instead of the traditional face-to-face classroom setting (Thomas, 2010). The lack of in-person support to help students understand the material and assignments may have had a large effect on the students' performance. Another aspect of virtual learning that could influence students' ability to learn is maintaining motivation (Gilbert, 2015). The abrupt transition from in-person learning to the virtual platform may have affected students' motivation levels, resulting in lower quality and missing work. Students with a decreased ability for self-regulation have been shown to not assign enough time to complete assignments, leading to poor quality work or late work (You \& Kang, 2014).

Although the switch to virtual learning may have been difficult, students in the CCRC still reported an increase in 7 out of the 9 areas in the life skills post-survey. The increase in positive student responses highlights the effectiveness of the life skills unit, even in a virtual delivery model. The virtual component allowed for the use of new tools and technology to engage students and incorporate new ways of learning. Many students enjoyed the addition of new learning materials such as YouTube videos, mentimeter polls, and virtual jeopardy. These learning tools may have not been previously explored, however, they proved to be an essential part of the life skills program to keep students engaged. Occupation-based class activities and assignments were also essential components of the life skills program. Participating in occupation-based activities and assignments allowed students to apply the use of life skills to themselves. By having students reflect on the use of life skills in their own lives, we enhance the meaningfulness of the skill. Through these occupation-based activities and assignments, students were better able to understand and apply the life skill being taught, leading to more confidence in 
the topic as displayed through the post-survey results. Overall, the change to virtual learning allowed for the development of an effective life-skills program and the use of new modes of delivery of information.

\section{Future Development of Program}

The life skills curriculum for the CCRC and health class was developed and implemented throughout the 14 week program at Winston. Due to the Covid-19 pandemic, the experiential portion of this program was not possible. Research has shown that experiential activities can play a significant role in the classroom. Students who receive hands-on, authentic experiences may develop curiosity and a desire to learn more (NRC, 2009). Through hands-on experience, students are better able to connect previous knowledge and experiences with the new concepts (Behrendt \& Franklin, 2014). Experiential aspects of curriculum help students develop a positive attitude for learning and motivate them to develop connections between theoretical concepts in the classroom and what has been experienced (Falk, Martin,\& Balling, 1978; Hudak, 2003). Future implementation of this program should include experiential community outings to help students practice implementing life skills. The location of the community outings should be chosen based on multiple factors including funding for transportation and staff available for supervision. Some examples of potential community outings include going to restaurants to practice money management, dorms to practice instrumental activities of daily living (IADLs) such as cleaning and laundry, and grocery stores to practice IADLs such as shopping. A focus group should be conducted at the end of implementation of the life skills program to gather feedback from the students.

Future development of this program should also include dispersion of material into other classes and lower grades. Life skills should be part of ongoing curriculum rather than isolated 
tasks separated from content normally covered (Cronin, 1996). Life skills lessons should be implemented in a variety of subject areas as a way of emphasizing the relationship of the academic topic to everyday activities (Cronin, 1996). Life skills should also begin to be integrated into the curriculum of younger students in order to help build on these concepts throughout school. Teaching students' key life skills early on can set them up to lead successful lives post-transition.

Pre- and post- life skills surveys were used to gain information on the students' level of knowledge on each life skill topic. Future life skills surveys should focus on gathering additional feedback on the students' perspectives of the program. Information on aspects of the program that they found helpful and areas for improvement should be collected. Learning this information would help the continued development and improvement of this transition program to help student better prepare for the next steps after high school.

\section{Implications for Occupational Therapy}

Occupational therapists play a unique role in the transition process to postsecondary education. OTs role in promoting life skills through a transition program has been shown to be beneficial for students. Occupational therapists are able to help students gain important life skills through occupation based programming, as evidenced through the CCRC and health class at Winston. Students are able practice application of valuable skills through unique occupationbased activities tailored to their environment and learning abilities. Emphasizing occupational therapist's role in the transition team will allow for more opportunities to assist students with this important life change. The development, implementation, and evaluation of this program can help open the door for occupational therapist's role in the transition process, especially in the area of life skills. 


\section{Sustainability of Life Skills Program}

In order to maintain the life skills program at the Winston School, class materials were organized in a shared google drive to allow for easy access for staff members. Class lectures, activities, and assignments were organized into individual folders under each corresponding life skill topic. Organization of the shared google drive was discussed with the occupational therapist guiding the CCRC at Winston. Although the life skills curriculum was developed for the CCRC, it has been designed for easy use in other subjects and grade levels. Class lectures contain notes on each slide in order to make it simple for staff members to teach in other classes. Class activities and assignments have detailed instructions, with some assignments containing a sample to help guide teachers as well as students. By making the program materials accessible and providing guidance for dispersing information, the life skills program will be more sustainable at the Winston School.

\section{Conclusion}

Occupational therapist practitioners play a vital role in the transition process, contributing to positive outcomes amongst youth (Eismann et al., 2017). Occupational therapists are able to develop prevocational programs, facilitate functions living skills development, modify environments, and help educate parents and staff (Spencer et al., 2003). Three occupational therapy doctoral students have attended Winston as their doctoral sites, focusing on the different aspects of transition. A comprehensive program was created focusing on three areas important for transition: financial literacy, college and career readiness, and life skills. Combined, these topics can help prepare students for the transition out of high school. Life skills are an important area to address in school in order to help students increase their independence and autonomy (Abaoğlu et al., 2017). Life skills are important to help students' deal with challenges that may 
arise in life and to promote physical, mental, and emotional well-being and competence (Abaoğlu et al., 2017). Occupational therapists can help students create individualized goals through life skills curriculum (Abaoğlu et al., 2017). By gaining important life skills such as selfcare, meal-preparation, coping with stress, and community access, students at Winston will be better prepared to take on life post- high school. 


\section{References}

Abaoğlu, H., Cesim, Ö.B., Kars, S., \& Çelik, Z. (2017). Life Skills in Occupational Therapy. https://doi.org/10.5772/intechopen.68462

Adreon, D., \& Durocher, J. S. (2007). Evaluating the college transition needs of individuals with high-functioning autism spectrum disorders. Intervention in School and Clinic, 42(5), 271-279. https://doi.org/10.1177/10534512070420050201

American Occupational Therapy Association. (2000). Standards of practice for occupational therapy. American Journal of Occupational Therapy, 52, 866-9. https://ajot.aota.org/article.aspx?articleid=1872133

American Occupational Therapy Association. (2002). Occupational therapy practice framework: Domain and process. American Journal of Occupational Therapy, 56, 60939. https://doi.org/10.5014/ajot.2014.682006

Aquilino, W. (2006). Family relationships and support systems in emerging adulthood. In J. J. Arnett \& J. L. Tanner, (Eds.), Emerging adults in America: Coming of age in the $21^{\text {st }}$ century (pp.193-217). https://doi.org/10.1037/11381-008

Ashbaugh, K., Koegel, R. L., \& Koegel, L. K. (2017). Increasing social integration for college students with Autism Spectrum Disorder. Behavioral Development Bulletin, 22(1), 183196. http://dx.doi.org/10.1037/bdb0000057

Baer R. M., Flexer R. W., Beck S., Amstutz N., Hoffman L., Brothers J., Stelzer D., Zechman C. (2003) A collaborative follow up study on transition service utilization and post-school outcomes. Career Development for Exceptional Individuals 26, 7-25. https://doi.org/10.1177/088572880302600102

Bangser, Michael. (2008). Preparing high school students for successful transitions to 
postsecondary education and employment. Issue Brief. National High School Center. https://www.mdrc.org/sites/default/files/PreparingHSStudentsforTransition_073108.pdf

Behrendt, M., \& Franklin, T. (2014). A review of research on school field trips and their value in education. International Journal of Environmental and Science Education, 9(3), 235-245. https://doi.org/10.12973/ijese.2014.213a

Benz M. R., Lindstrom L. E. \& Yovanoff P. (2000) Improving graduation and employment outcomes of students with disabilities: Predictive factors and student perspectives. Exceptional Children 66, 509-29. https://doi.org/10.1177/001440290006600405

Beverly, S. G., \& Burkhalter, E. K. (2005). Improving the financial literacy and practices of youths. Children \& Schools,27(2), 121-124. https://doi.org/10.1093/cs/27.2.121

Bouck, E. C. (2010), Reports of life skills training for students with intellectual disabilities in and out of school. Journal of Intellectual Disability Research, 54: 1093-1103. https://doi.org/10.1111/j.1365-2788.2010.01339.x

Burrus, Jeremy. (2014). Broadening the definition of college and career readiness: A holistic approach. https://files.eric.ed.gov/fulltext/ED555591.pdf

Chaney E. G. (2001). Web-based instruction in a rural high school: A collaborative inquiry into its effectiveness and desirability. NASSP Bulletin, 85(628), 20-35. https://doi.org/10.1177/019263650108562803

Christiansen, C., \& Baum, C.M. (2005). Occupational therapy: Enabling function and wellbeing ( $3^{\text {rd }}$ ed.). SLACK Incorporated.

Cleary, D. S., Persch, A. C., \& Spencer, K. (2015). Transition to adulthood. In J. Case-Smith \& J. C. O’Brien (Eds.), Occupational therapy for children and adolescents $\left(7^{\text {th }}\right.$ ed., pp. 727746). St. Louis, Missouri. 
Conley, D. T. (2012). A complete definition of college and career readiness.

Educational Policy Improvement Center. https://files.eric.ed.gov/fulltext/ED537876.pdf

Cronin, M. E. (1996). Life skills curricula for students with learning disabilities: A review of the literature. Journal of Learning Disabilities, 29(1), 53-68. https://doi.org/10.1177/002221949602900108

Donlevy, J. (2003). Teachers, technology and training: Online learning in virtual high school. International Journal of Instructional Media, 30(2), 117-121.

Eisenberg, D., Golberstein, E., Hunt, J. (2009). Mental health and academic success in college. The B.E. Journal of Economic Analysis \& Policy. 9, 40. http://wwwpersonal.umich.edu/ daneis/symposium/2010/ARTICLES/eisenberg_golberstein_hunt_2 009.pdf

Eismann,M. M., Weisshaar, R., Capretta, C., Cleary, D. S., Kirby, A. V., \& Persch, A. C. (2017). Characteristics of students receiving occupational therapy services in transition and factors related to postsecondary success. American Journal of Occupational Therapy, 71(3), 1-9. https://doi.org/10.5014/ajot.2017.024927

Erikson, E.H., Erikson, J.M. (1997). The life cycle completed. Norton.

Falco, L. D., \& Steen, S. (2018). Using school-based career development to support college and career readiness: An integrative review. Journal of School-Based Counseling Policy and Evaluation, 1(1). https://doi.org/ 10.25774/v1t4-c816

Falk, J. H., Martin, W. W., \& Balling, J. D. (1978). The novel field trip phenomenon: Adjustment to novel settings interferes with task learning. Journal of Research in Science Teaching,15(2), 127-134. https://doi.org/10.1002/tea.3660150207

Fier, S. M., \& Brzezinski, L. G. (2010). Facilitating the high school-to-college transition for 
students with psychiatric disabilities: Information and strategies for school counselors. Journal of School Counseling, 8(10). https://jsc.montana.edu/articles/v8n10.pdf

Gajar A., Goodman L. \& McAfee J. (1993) Secondary schools and beyond: Transition of individuals with mild disabilities. Merrill

Gil, L. A. (2007). Bridging the transition gap from high school to college: Preparing students with disabilities for a successful postsecondary experience. TEACHING Exceptional Children, 40(2), 12-15. https://doi.org/10.1177/004005990704000202

Gilbert, B. (2015). Online Learning Revealing the Benefits and Challenges. https://fisherpub.sjfc.edu/cgi/viewcontent.cgi?article=1304\&context=education_ETD_ma $\underline{\text { sters }}$

Hamblet, E. C. (2014). Nine strategies to improve college transition planning for students with disabilities. Teaching Exceptional Children, 46(3), 53-59. https://doi.org/10.1177/004005991404600306

Hartley, M. T. (2012). Assessing and promoting resilience: An additional tool to address the increasing number of college students with psychological problems. Journal of College Counseling, 15, 37-51. https://doi.org/ 10.1002/j.2161-1882.2012.00004.x

Harvey M. W. (2002) Comparison of postsecondary transitional outcomes between student with and without disabilities by secondary vocational education. Career Development for Exceptional Individuals 24, 99-122. https://journals.sagepub.com/doi/abs/10.1177/088572880202500202?journalCode=cdea

Holt, N. L., Tink, L. N., Mandigo, J. L., \& Fox, K. R. (2008). Do youth learn life skills through their involvement in high school sport? A case study. Canadian Journal of Education, 31(2), 281-304. https://doi.org/10.2307/20466702 
Hudak, P. (2003). Campus field exercises for introductory geoscience courses. Journal of Geography, 102(5), 220-225. https://doi.org/10.1080/00221340308978550

Janiga, S. J., \& Costenbader, V. (2002). The transition from high school to postsecondary education for students with learning disabilities: A survey of college service coordinators. Journal of Learning Disabilities, (5), 462. https://doi.org/10.1177/00222194020350050601

Job, J. M., Klassen, R. M. (2012). Predicting performance on academic and nonacademic tasks: A comparison of adolescents with and without learning disabilities. Contemporary Educational Psychology, 37(2), 162-169. https://doi.org/10.1016/j.cedpsych.2011.05.001

Kardos M, \& White BP. (2005). The role of the school-based occupational therapist in secondary education transition planning: A pilot survey study. American Journal of Occupational Therapy, 59(2), 173-180. https://doi.org/10.5014/ajot.59.2.173

Kaye, H. S., Jans, L. H., \& Jones, E. C. (2011). Why don’t employers hire and retain workers with disabilities?. Journal of occupational rehabilitation, 21(4), 526-536. https://doi.org/10.1007/s10926-011-9302-8

King, G., Kingsnorth, S., McPherson, A., Jones-Galley, K., Pinto, M., Fellin, M., Savage, D. (2016). Residential immersive life skills programs for youth with physical disabilities: A pilot study of program opportunities, intervention strategies, and youth experiences. Research in Developmental Disabilities, 55, 242-255. https://doi.org/10.1016/j.ridd.2016.04.014

Klassen, R. (2002). A question of calibration: A review of the self-efficacy of students 
with learning disabilities. Learning Disability Quarterly, 25, 88-102. https://doi.org/10.2307/1511276

Klassen, R. M. (2007). Using predictions to learn about the self-efficacy of early adolescents with and without learning disabilities. Contemporary Educational Psychology, 32, 173-187. https://doi.org/10.1016/j.cedpsych.2006.10.001

Laursen, B., \& Collins, W. A. (2009). Parent-child relationships during adolescence. In R. M. Lerner \& L. Steinberg (Eds.), Handbook of adolescent psychology: Contextual influences on adolescent development (p. 3-42). John Wiley \& Sons, Inc.. https://doi.org/10.1002/9780470479193.adlpsy002002

Lerner \& L. Steinberg (Eds.), Handbook of adolescent psychology: Contextual influences on adolescent development ( $3^{\text {rd }}$ ed., Vol. 2, pp. 3-42). Wiley.

Law, M., Cooper, B., Strong, S., Steward, D., Rigby, R., \& Letts, L. (1996). The personenvironment-occupational model: A transactive approach to occupational performance. Canadian Journal of Occupational Therapy, 63, 9-23. https://doi.org/10.1177/000841749606300103

Levinson, D. (1978). The seasons of a man's life. Ballentine Books.

Life Skills Inventory Independent-Living Skills Assessment Tool. (n.d.). https://transitioncoalition.org/blog/assessment-review/life-skills-inventory-independent$\underline{\text { living-skills-assessment-tool/ }}$

Lindsay, S., R. Hartman, L., \& Fellin, M. (2016). A systematic review of mentorship programs to facilitate transition to post-secondary education and employment for youth and young adults with disabilities. Disability \& Rehabilitation, 38(14), 1329-1349. https://doi.org/10.3109/09638288.2015.1092174 
Mazzotti, V. L., \& Rowe, D. A. (2015). Meeting the transition needs of students with disabilities in the $21^{\text {st }}$ Century. TEACHING Exceptional Children, 47(6), 298-300. https://doi.org/10.1177/0040059915587695

Michaels, C. \& Orentlicher, M. (2004). The role of occupational therapy in providing person-centered transition services: Implications for school-based practice. Occupational Therapy International, 11. 209-28. https://doi.org/10.1002/oti.212

Michel, N., Cater, J. J., \&amp; Varela, O. (2009). Active versus passive teaching styles: An empirical study of student learning outcomes. Human Resource Development Quarterly, 20(4), 397-418. https://doi.org/10.1002/hrdq.20025

Mosey, A.C. (1986). Psychosocial components of occupational therapy. Raven.

Nasheeda, A., Abdullah, H. B., Krauss, S. E., \& Ahmed, N. B. (2018). A narrative systematic review of life skills education: effectiveness, research gaps and priorities. International Journal of Adolescence and Youth, 24(3), 362-379. https://doi.org/10.1080/02673843.2018.1479278

National Association of Manufacturers, Manufacturing Institute's Center for Workforce Success, and Deloitte Consulting. (2005). 2005 skills gap report: A survey of the American manufacturing workforce. Deloitte Development LLC.

National Research Council (2009). Learning science in informal environments: People, places, and pursuits. Washington, DC: The National Academies Press.

Nellie Mae. (2002). Undergraduate students and credit cards: An analysis of usage rates and trends. https://www.immagic.com/eLibrary/ARCHIVES/FIN_AID/SALMAEUS/N050524U.pdf

Newman, L., Wagner, M., Knokey, A. M., Marder, C., Nagle, K., Shaver, D., \& Wei, X. (2011). 
The post-high school outcomes of young adults with disabilities up to 8 years after high school: A report from the National Longitudinal Transition Study-2. SRI International.

Nguyen, T., Stewart, D., \& Gorter, J. W. (2018). Looking back to move forward: Reflections and lessons learned about transitions to adulthood for youth with disabilities. Child: Care, Health \& Development, 44(1), 83-88. https://doi.org/10.1111/cch.12534

Nordstrom, A. H., Goguen, L. M. S., \& Hiester, M. (2014). The effect of social anxiety and selfesteem on college adjustment, academics, and retention. Journal of College Counseling, (1), 48. https://doi.org/10.1002/j.2161-1882.2014.00047.x

Oakes, J., \& Saunders, M. (2007). Multiple pathways: High school reform that promises to prepare all students for college, career, and civic responsibility. Multiple perspectives on multiple pathways: Preparing California's youth for college, career, and civic responsibility. University of California.

Parvathy, V., \& Pillai, R. R. (2015). Impact of life skills education on adolescents in rural school. International Journal of Advanced Research, 3(2), 788-794. https://www.researchgate.net/publication/308368929_Impact_of_life_skills_education_o $\underline{\text { n_adolescents_in_rural_school }}$

Riches V., Parmenter T., Fegent M. \& Bailey P. (1993) Secondary education: A follow-along study of students with disabilities in transition in New South Wales (ED358627).ERIC. https://eric.ed.gov/?id=ED358627

Romppel, M., Herrmann-Lingen, C., Wachter, R., Edelmann, F., Düngen, H. D., Pieske, B., \& Grande, G. (2013). A short form of the General Self-Efficacy Scale (GSE-6): Development, psychometric properties and validity in an intercultural non-clinical sample and a sample of patients at risk for heart failure. Psycho-social medicine, 10, Doc01. 
https://doi.org/10.3205/psm000091

Rovai, A. P., Wighting, M. J., \& Liu, J. (2005). School climate: Sense of classroom and school communities in online and on-campus higher education courses. Quarterly Review of Distance Education, 6(4), 361-374. http://search.proquest.com/docview/231071527?accountid=27700

Royster, P., Gross, J. \& Hochbein, C. (2015). Timing is everything: Getting students back on track to college readiness in high school. The High School Journal 98(3), 208-225. The University of North Carolina Press. http://www.jstor.org/stable/44075294

Savenye, W.C. (2005). Improving online courses: What is interaction and why use it? (Undetermined). Distance Learning, 2(6), 22-28.

Spencer JE, Emery LJ, \& Schneck CM. (2003). Occupational therapy in transitioning adolescents to post-secondary activities. American Journal of Occupational Therapy, 57(4), 435-441. https://doi.org/10.5014/ajot.57.4.435

Swank, J. M., \& Huber, P. (2013). Employment preparation and life skill development initiatives for high school students with emotional and behavioral disabilities. The Professional Counselor,3(2), 73-81. https://files.eric.ed.gov/fulltext/EJ1063191.pdf

Taylor, Z. E., Doane, L. D., \& Eisenberg, N. (2014). Transitioning from high school to college: Relations of social support, ego-resiliency, and maladjustment during emerging adulthood. Emerging Adulthood, 2(2), 105. https://doi.org/10.1177/2167696813506885

Teyhan, A., Cornish, R., Macleod, J., Boyd, A., Doerner, R., \& Sissons Joshi, M. (2016). An evaluation of the impact of "life skills" training on road safety, substance use and hospital attendance in adolescence. Accident Analysis and Prevention, 86, 108-113. https://doi.org/10.1016/j.aap.2015.10.017 
Thomson, L. D. (2010). Beyond the classroom walls: Teachers' and students' perspectives on how online Llarning can meet the needs of gifted students. Journal of Advanced Academics, 21(4), 662-712. https://doi.org/10.1177/1932202X1002100405

Tuttle, J., Campbell-Heider, N., \& David, T. M. (2006). Positive adolescent life skills training for high-risk teens: Results of a group intervention study. Journal of Pediatric Health Care, 20(3), 184-191. https://doi.org/10.1016/j.pedhc.2005.10.011

United Nations Children's Fund (UNICEF). (2012). Global evaluation of life skills education programmes.

U.S. Department of Labor. (2014). Economic picture of the disability community project: Key points on disability and occupational projections tables. https://www.dol.gov/odep/pdf/20141022-KeyPoints.pdf

Venezia, Andrea \& Jaeger, Laura. (2013). Transitions from high school to college. The Future of Children. 23. 117-136. http://doi.org/10.2307/23409491.

Vogelsberg, R. (1980). Programming for apartment living: A description and rationale of an independent living skills Inventory. Journal of the Association for the Severely Handicapped. https://doi.org/10.1177/154079698000500105

Wehman, P., Sima, A., Ketchum, J., West, M., Chan, F., \& Luecking, R. (2015). Predictors of successful transition from school to employment for youth with disabilities. Journal of Occupational Rehabilitation, 25(2), 323-334. https://doi.org/ 10.1007/s10926-014-9541$\underline{6}$

Wehman, P. (2013). Life beyond the classroom: Transition strategies for young people with disabilities. Brookes.

You, J. W. , \& Kang, M. (2014) The role of academic emotions in the relationship between 
perceived academic control and self-regulated learning in online learning. Computers \&

Education, 77, 125-133. https://doi.org/10.1016/j.compedu.2014.04.018 
Appendix A

\section{Life Skills Student Interest Survey}

1) Enter your name

2) Pick 6 areas of life skills that you would like to focus on during this unit

a) Self-care

b) Sleep

c) Conflict resolution

d) Home management/independent living

e) Food and Nutrition

f) Health/medication management

g) Community mapping

h) Time management

i) Positive recreation \& leisure

j) Stress Management

3) Are there any other areas of life skills you would like to learn about? 


\section{Appendix B}

\section{Life Skills Staff Interest Survey}

1) What subject(s) and grade(s) do you teach?

2) Which of the following areas of life skills do you see your students having the most difficulty with?
a) Self-care
b) Sleep
c) Conflict resolution
d) Home management/independent living
e) Food and nutrition
f) Health/medication management
g) Community mapping
h) Time management
i) Positive recreation and leisure
j) Stress management

3) Are there any other areas of life skills not listed above that you see your students having difficulty with? 


\section{Appendix C}

\section{Life Skills Pre-Survey}

1) Enter your name

2) What are some examples of life skills you may need after high school?

3) What life skills do you feel confident with?

4) What are some examples of life skills you have difficulties with?

5) I know how to manage my mental health (how I think, feel and act) 1-5

6) I know how to manage my emotional health (awareness of your emotions and ability to express them appropriately) 1-5

7) I know how to manage my physical health 1-5

8) I am able to maintain a good sleep routine (fall asleep easily, stay asleep, get $8+$ hours of sleep a night) $1-5$

9) I know how to maintain my living space (e.g., home repairs, cleaning) 1-5

10) I know how to choose healthy meals and snacks $1-5$

11) I know how to manage my health independently (i.e. where to go when I am sick) 1-5

12) I know how to balance my time well (e.g. time with friends, school, self-care) 1-5

13) I am able to manage my stress levels well 1-5

14) What strategies do you use to manage your stress?

15) I am able to resolve conflicts with others 1-5

16) What strategies do you use to resolve conflicts with others?

17) What is a goal you have for yourself related to life skills? 


\section{Appendix D}

\section{Life Skills Post-Survey}

1) Enter your name

2) I know how to manage my mental health (how I think, feel and act) 1-5

3) I know how to manage my emotional health (awareness of your emotions and ability to express them appropriately)

4) I know how to manage my physical health 1-5

5) I know how to maintain a good sleep routine (fall asleep easily, stay asleep, get $8+$ hours of sleep a night) $1-5$

6) I know how to maintain my living space (e.g., home repairs, cleaning) 1-5

7) I know how to choose healthy meals and snacks 1-5

8) I know how to manage my health independently (i.e. where to go when I am sick) 1-5

9) I know how to balance my time well (e.g. time with friends, school, self-care) 1-5

10) I know how to manage my stress levels well 1-5

11) I know how to resolve conflicts with others $1-5$

12) What strategies can you use to resolve conflicts with others?

13) Why do you think it is important to learn about life skills?

14) Do you feel more confident after the life skills unit? Why or why not? 


\section{Appendix E}

\section{Health Class Survey}

1) How knowledgeable do you feel about self-care after this class? 1-5

2) What did you learn about self-care in this class?

3) How knowledgeable do you feel about food \& nutrition after this class? 1-5

4) What did you learn about food \& nutrition in this class?

5) How knowledgeable do you feel about time management after this class? 1-5

6) What did you learn about time management in this class?

7) How knowledgeable do you feel about stress management after this class? 1-5

8) What did you learn about stress management in this class? 


\section{Appendix F}

\section{Self-Care Outline}

Self- Care

By: Rupa Parikh, OTDS

- Definition

Self-care is "the ability of individuals, families and communities to promote health, prevent disease, maintain health, and to cope with illness and disability with or without the support of a healthcare provider"

- Areas of Health

Mental health: How we think, feel, and act

Emotional health: Awareness of your emotions and ability to express them appropriately Physical health: The condition of your body

- Mental Health

Mental Health includes our psychological, emotional, and social well-being It can affect how we think, feel and act Can be affected by a variety of factors:

1. Biological factors (i.e. genes \& brain chemistry)

2. Life experiences (i.e. trauma \& stress)

3. Family history of mental health conditions

- Tips for good mental health

Getting enough sleep, eating healthy, connecting with others, engaging in physical activity, developing coping skills, asking for help when needed

- Emotional health 
Your ability to manage and express emotions that arise. How you feel can affect your everyday activities. Emotional wellness is your ability to successfully handle life's stressors when needed

- Strategies for improving emotional health

1. Brighten your outlook

2. Reduce stress

3. Get quality sleep

4. Be mindful

5. Strengthen social connections

- Physical health

Your physical health is the result of how you treat your body

Good physical health can positively affect your overall well-being

- Factors that contribute to good physical health

Exercise, nutrition, good personal hygiene, proper sleep

- Assignment

Self-Care Bingo

References

10 top tips for good mental health. 10 top tips for good mental health - People First. https://www.peoplefirstinfo.org.uk/health-and-well-being/mental-health/10-top-tips-forgood-mental-health/.

Meaningful life - Physical health. Head to Health. https://headtohealth.gov.au/meaningfullife/physical-health.

Orenstein, B. W., Rauf, D., Dolan, M., Colino, S., Ellin, A., \& Zuppello, S. A Guide to Good 
Personal Hygiene - Healthy Living Center. EverydayHealth.com.

https://www.everydayhealth.com/healthy-living/guide-to-good-hygiene.aspx.

Pyramid Healthcare. (2019, July 9). Differences Between Mental Health \& Emotional Health:

PFBH Assessment Center. Pyramid Healthcare.

https://www.pyramidhealthcarepa.com/pyramid-healthcare-assessment-center/pfbhassessment-center-blog/what-is-the-difference-between-mental-health-emotional-health.

Seppala, D. E. (2017, June 28). Connectedness \& Health: The Science of Social Connection. The Center for Compassion and Altruism Research and Education.

http://ccare.stanford.edu/uncategorized/connectedness-health-the-science-of-socialconnection-infographic/.

U.S. Department of Health and Human Services. Sleep Deprivation and Deficiency. National Heart Lung and Blood Institute. https://www.nhlbi.nih.gov/health-topics/sleep-deprivationand-deficiency.

What do we mean by self-care? (2019, May 15). https://www.who.int/reproductivehealth/selfcare-interventions/definitions/en/.

What Is Mental Health? What Is Mental Health?| MentalHealth.gov. https://www.mentalhealth.gov/basics/what-is-mental-health. 


\section{Appendix G}

\section{Sleep Outline}

Sleep

Getting your zzzzzz's toget your aaaaaa's

By Chelsea Van Gorder,OTDS

- Mentimeter

Go to www.menti.com

Type in code 664600

- $\quad$ Sleep facts

Adolescents receive 7 hours of sleep but need 9-9.5 hours

College students receive about 6 hours of sleep but need 8 hours

$60 \%$ of college students suffer from poor quality sleep

- Key terms

Sleep duration: how many hours you sleep

Sleep quality: how well you sleep

Biological clock: a natural system within the body that can affect a person's sleep-wake cycles

Melatonin: a substance the body produces that helps control the body's sleep-wake cycles

- What would happen if you didn't sleep?

https://www.youtube.com/watch?v=dqonk4815vy

- What does sleep affect?

Attention, thought processes, health, mood, safety

- Mentimeter

Go to www.menti.com 
Type in code 664600

- What affects sleep duration and quality?

Stress, day napping, caffeine, screen time, environmental factors

- $\quad$ Sleep tips

Prepare for sleep by creating a sleep routine

Avoid oversleeping on weekends

Create a sleep conducive environment

Exercise Regularly

Finish eating at least 2-3 hours before your regular bedtime

Perform stress management strategies to cope with stress

References

Sclarb, a. A., friedrich, a., \& classe, m. (2017). Sleep problems in university students - an intervention. Neuropsychiatric disease and treatment, 13, 1989-2001. Doi: $10.2147 /$ ndt.s 142067

Worley, s. L. (2018). The extraordinary importance of sleep: the detrimental effects of inadequate sleep on health and public safety drive an explosion of sleep research. $P \& t: a$ peer-reviewed journal for managed care \& formulary management, 43(12), 758-763. Retrieved from http://search.ebscohost.com/login.aspx?direct=true \&db=ccm\&an=133417593\&site=eds$\underline{\text { live }}$ 


\section{Appendix $\mathbf{H}$ \\ Conflict Resolution}

Conflict Resolution

By: Rupa Parikh, OTDS

- What is conflict?

"Conflict is a struggle or tension through which the parties involved perceive a threat to their needs, interests or concerns."

\section{- Scenarios where you may use conflict resolution}

At work with employees, group projects, with roommates, with friends/family members

- How do you approach a conflict?

Modified Thomas Killmann Questionnaire

- Interpret your results

A high score in a column would be an 8 or 9 , a medium score a 5, 6, or 7, and a low score 3 or 4

- 5 Steps to Conflict Resolution

Define the source of conflict, look beyond the incident, request solutions, identify solutions both sides can support, agreement

- Strategies for conflict resolution

Communication is key

- $\quad$ Active Listening

Reflecting, restating, validating, encouraging, clarifying, summarizing

- Observations vs. Judgments

Observations: Describe what you actually see and hear without involving perceptions or assumptions 
Judgments: When we start to put perceptions, assumptions and biases into the mix When we communicate using judgments, people can get defensive and respond in anger Instead, we should communicate using observations of the situation and our needs in order to shift away from blame and focus on the problem we would like to solve - Modified Thomas Killmann Questionnaire:

Fill out:

https://static1.squarespace.com/static/537e4a6ce4b0ded903cd630e/t/5e751e347fdc5c0278fe14fa/ 1584733748672/Thomas+Kilman+Model.pdf

References

Communication Skills. School Tools. https://www.schooltools.info/communication-skills.

The Five Steps to Conflict Resolution. AMA. https://www.amanet.org/articles/the-five-steps-toconflict-resolution/.

Kilmann. (2020, May 17). Take the Thomas-Kilmann Instrument: Improve How You Resolve Conflict. https://kilmanndiagnostics.com/overview-thomas-kilmann-conflict-modeinstrument-tki/.

School Tools Conflict Resolution Education Lesson Plans: Conflict Resolution Resources. https://www.schooltools.info/. 


\section{Appendix I}

\section{Food \& Nutrition Outline}

Food and Nutrition

By: Rupa Parikh, OTDS

- What is good nutrition?

Good nutrition means giving your body all the vitamins, nutrients, and minerals it needs to work at its best

- The Numbers

About one-third of U.S. adults (33.8\%) are obese Approximately 17\% (or 12.5 million) of children and adolescents aged 2-19 years are obese Even for people at a healthy weight, a poor diet is associated with major health risks that can cause illness and even death

- Benefits of good nutrition

Reduces the risk of some diseases such as diabetes, heart disease, stroke, and osteoporosis

Reduces high blood pressure

Lower high cholesterol

Increase energy level

Increased ability to fight of illness

- What is MyPlate?

Tips on finding your healthy eating style

Focuses on variety, amount, and nutrition

The right mix of foods and drinks can help you be healthier now, and in the future

- Tips for incorporating fruits into your diet 
Choose whole fruits more often than fruit juice (includes fresh, frozen, canned, dried, and pureed fruit). Choose options with little to no added sugar

Keep a bowl of fruit on your countertop. It is easier to choose a healthy snack when it is in plain sight!

Add fruit into all your meals. (i.e. bananas with breakfast, fruit in your salads, pineapple in a fried rice).

Focus on fruits at breakfast (i.e. add fruits into your cereal or yogurt)

- $\quad$ Tips for varying your veggies

Enjoy your veggies raw or cooked: fresh, frozen, canned, or dried. You can eat them whole, cutup, or mashed!

Brighten up your plate with vegetables that are orange, red, and dark green- they are filled with vitamins and minerals!

Add veggies to dishes such as sandwiches, wraps, tacos, or omelets

Eat them as a side or with a dip!

- Tips for adding grains to your diet

Look for the words " $100 \%$ whole grain or $100 \%$ whole wheat" on food labels. Whole grains provide more nutrients than refined grains

Make some substitutes! Instead of having a sandwich on white (refined) bread, use 100\% whole wheat pita bread, whole grain tortillas, or whole wheat wraps

- Tips to vary your protein routine

Eat a variety of foods from the Protein Foods Group each week. Experiment with beans or peas, nuts, soy, and seafood as main dishes. 
Eat plant-based protein foods more often ( i.e. beans, split peas, chickpeas, hummus, soy products, nut and seeds). They are lower in saturated fat and some are higher in fiber Select lean meat and poultry. Choose lean cuts of meat like round or sirloin and ground beef that is at least $93 \%$ lean. Trim or drain fat from meat and remove poultry skin.

- How to add dairy to your diet

The Dairy Group includes milk, yogurt, cheese, and fortified soy beverages (soymilk). They provide nutrients you need including- calcium, vitamin D, potassium, protein, and more! Make dairy part of your meal.

Try using plain low-fat yogurt or ricotta cheese instead of sour cream or cream cheese.

- Ways to get calcium if you do not consume milk products

Calcium-fortified juices, cereals, breads, rice milk, or almond milk

Canned fish (sardines, salmon with bones)

Soybeans, soy products (tofu made with calcium sulfate, soy yogurt, tempeh), and some other beans

Some leafy greens (collard and turnip greens, kale, bok choy)

- Healthy Snack Options

- Snacking can be good in moderation

Smart snacking can make you feel more energized

- First: Munchies that crunch

- Second: Rethink your drink

- Third: Snacks that satisfy

- Finally: Snacks to curb your sweet tooth

- How to Understand and Use the Nutrition Facts Label 


\section{- Serving Size}

Serving size is the amount of servings per container

The serving size reflects the amount that people typically eat or drink. It is not a recommendation of how much you should eat or drink

Pay attention to the serving size

- Calories

Calories refers to how much energy you get from a serving of this food or drink - Nutrients

Look for foods that contain more of the nutrients you want to get more of and less of the nutrients you may want to limit

Nutrients to get less of: Saturated Fat, Sodium, and Added Sugars

Nutrients to get more of: Dietary Fiber, Vitamin D, Calcium, Iron, and Potassium

- $\quad$ The Percent Daily Value (\%DV)

- The $\% \mathrm{DV}$ is percent of the Daily Value for each nutrient in a serving of the food

- Assignment Directions

https://www.accessdata.fda.gov/scripts/InteractiveNutritionFactsLabel/\#intro

References

Case-Lo, C. (806AD, April 10). Food \& Nutrition. Healthline.

https://www.healthline.com/health/food-nutrition.

Center for Food Safety and Applied Nutrition. How to Understand and Use the Nutrition Facts Label. U.S. Food and Drug Administration. https://www.fda.gov/food/new-nutrition-factslabel/how-understand-and-use-nutrition-facts-label.

Healthy Snacking. www.heart.org. https://www.heart.org/en/healthy-living/healthy-eating/add- 
color/healthy-snacking.

The Importance of Good Nutrition: Tufts Health Plan Medicare Preferred.

https://www.tuftsmedicarepreferred.org/healthy-living/expert-knowledge/importance-goodnutrition.

MyPlate Graphic Resources. ChooseMyPlate.

https://www.choosemyplate.gov/resources/myplate-graphic-resources.

US Department of Health and Human Services. (2017, January 26). Importance of Good

Nutrition. HHS.gov. https://www.hhs.gov/fitness/eat-healthy/importance-of-goodnutrition/index.html. 


\section{Appendix J}

\section{Time Management Outline}

Time Management

By: Chelsea Van Gorder, OTDS

- $\quad$ Time Management

The ability to plan and control how much time you spend throughout the day to accomplish goals

- Why?

Demands and responsibilities of postsecondary activities

Long-term planning

Society's current need for immediacy leads to procrastination

Spend time on what matters

Need to understand HOW to use your time

- Time Management Strategies

Be Organized, reduce clutter, create a to-do list

- Know your energy levels

Monday: Energy ramps out of the weekend-schedule low-demand tasks like setting goals, organizing, and planning

Tuesday, Wednesday: Peak of energy-tackle the most difficult problems, write, brainstorm, schedule your make-up time

Thursday: Energy begins to ebb-schedule meetings, especially when consensus is needed

Friday: Lowest energy level-do open-ended work, long-term planning, and relationship building

- Eliminate Distractions 
Turn off notifications, use monitoring devices, place your phone in a new spot, wear headphones, think about work environment

- How to Prioritize

Make a list, rank the tasks, Eisenhower matrix

Set time limits and track your time

- How to beat the procrastination cycle

2-minute rule

Part 1: If the task can be completed in 2 minutes... do it now

Part 2: If the task will take longer than 2 minutes.. start it for 2 minutes

- Assignment

Prioritizing Using the Eisenhower matrix 


\section{Appendix K}

\section{Stress Management}

- Stress Management

- $\quad$ By: Rupa Parikh, OTDS

- What Is Stress?

Feeling of physical or emotional tension

Can arise from any thought or event that makes you feel frustrated, angry, or nervous

Stress is your body's reaction to a challenge or a demand

Stress can be positive in short bursts, such as when it helps you avoid danger or meet a deadline However, when stress lasts a long time it may be harmful to your health

- $\quad$ Types of Stress

Acute and chronic stress

- Physiological Effects of Stress

Your body reacts to stress by releasing hormones. These hormones make your brain more alert, cause your muscles to tense, and increase your pulse. In the short term, these reactions are good because they can help you handle the situation causing stress. This is your body's way of protecting itself.

Health problems: heart disease, obesity, diabetes, high blood pressure, depression or anxiety, skin problems

- $\quad$ Effects of Stress on Mental Health

Thinking ability

Jumbles and confused thoughts

Thinking becomes focused on worrying 
Preoccupation with problems

Lowered ability for decision making

Thinking negatively and fearing the worst increases worry and stress

- Common Emotions Experienced with Stress

Anger, anxiety, self-doubt, frustration, irritability, impatience, panic, depression

- $\quad$ Signs of Stress

Forgetfulness, headaches, lack of energy or focus, body aches and pains, tiredness, trouble sleeping or sleeping too much, upset stomach, weight loss or gain, diarrhea or constipation, stiff jaw or neck

- Causes of Stress for Students

Exams, deadlines, combination of work and school, difficulty in organization. poor time management, debt, housing problems, adjusting to a new environment, balance of social life and studying, difficulties with personal relationships, stress management techniques

- $\quad$ Breathing Exercise

The way you breathe affects your whole body. Breathing exercises are a good way to relax, reduce tension, and relieve stress

Deep breathing is one of the best ways to lower stress in the body.

Try this!

Place one hand on your chest and one on your stomach. As you breathe in through your nose, allow your stomach to swell. This means that you are using the diaphragm to breathe in and allowing air right down into your lungs. Try to keep the movement in your upper chest to a minimum and keep the movement gentle. Slowly and evenly breathe out through your nose. 
Repeat and get a rhythm going. You are aiming to take 8-12 breaths a minute - breathing in and breathing out again counts as one breath.

- References

- $\quad$ Stress and your health: MedlinePlus Medical Encyclopedia. https://medlineplus.gov/ency/article/003211.htm.

- Stress Management: Breathing Exercises for Relaxation. Stress Management: Breathing Exercises for Relaxation | Michigan Medicine. https://www.uofmhealth.org/healthlibrary/uz2255.

- University of St Andrews. Managing Stress | Current Students | University of St Andrews. https://www.st-andrews.ac.uk/students/advice/leaflets/stress/. 


\section{Appendix L}

\section{Independent Living and Home Management Outline}

Independent Living \& Home Management

By: Rupa Parikh, OTDS

- Independent Living After High School

Elect appropriate housing, establish and set up a household, use appliances and tools safely, maintain interior and exterior of home

- Housing Options

1. Living in an apartment

2. Living in a college dorm

3. Living with parents or relatives

- Living in an apartment

Find an apartment in a good location with a price in your budget

You will need to review and sign a lease

A lease outlines your rent, your rights and responsibilities, and who pays for and repairs what Consider other fees such as gas and electricity

- How to find an apartment

Establish your rental budget

Determine which neighborhoods work for you

List your must-have apartment amenities

Start your rental research

Tour apartments that meet your search criteria

- Possible Fees 
Rental application fee, apartment security deposit

- Apartment Lease

Make sure to read through your apartment lease and make sure you understand it before signing

Look to make sure the following questions are answered

1. What is the apartment maintenance process?

2. Are there restrictions on the number of roommates?

3. Are pets allowed, and if so, is there a deposit or pet rent required

4. What are the consequences of breaking your lease before the term is up?

5. Are you allowed to make any customizations, like hanging shelves or painting walls?

6. Which utilities are you responsible for paying?

- Living in a college dorm- what to expect

There will be rules

Most dorms have RA's (resident advisors)

Get to know your building

You will have roommates

Dorm rooms can be personalized

It's short term

- Tips to prepare for move in day

Limit who tags along, bring refreshments, forget about suitcases unless you are flying, check website for move-in policies, make the bed last, plan time for meetings on campus, pack with seasons in mind, find out where stores are ahead of time, bring cleaning supplies, relish the moment!

- Living with Parents or Relatives 
Discuss timeline, financials, expectations

- What do you need to do to maintain your home?

Cooking, doing laundry, housekeeping, staying safe, paying rent

- Housekeeping Tips

Keep dishes clean and don't let them pile up

Keep the refrigerator clean- check it weekly and throw out old food

Wash clothes weekly. Sort between dark clothes, jeans, and light clothes

Store clean laundry right away to avoid mixing it with the dirty clothes

Dust and vacuum weekly

Sort your mail between junk mail and bills and toss out what is not needed

Empty the garbage can when it's full and mark trash day on the calendar

Keep the bathroom toilet, shower and sink clean

Change sheets weekly

- In-Home Safety

Keep doors and windows locked at all times

Never allow anyone you don't know into your home

Always know who is at the door before opening it

Never tell anyone that you live alone or are home alone

- $\quad$ Fire Safety

Make sure your smoke detectors are working and you change the battery twice per year

Have a working fire extinguisher appropriate for all types of fire

If you have a gas appliance or heat, make sure you have a working carbon monoxide detector Never wear clothing with loose fitting sleeves when cooking 
Never leave your kitchen unattended if your stove is on

- Assignment

Chores Chart

- Example

References

Heffernan, L. (2016, August 3). Ready for College Move-In Day? Ten Tips to Help Parents and Teens Prepare. NBCNews.com. https://www.nbcnews.com/feature/college-game-plan/readycollege-move-day-ten-tips-help-parents-teens-prepare-n622106.

It's My Move. http://www.itsmymove.org/MyHome.php.

IvyWise. (2020, May 21). What to Expect Your First Year Living in a College Dorm. IvyWise. https://www.ivywise.com/blog/what-to-expect-your-first-year-living-in-a-college-dorm/.

Personal Needs. Pathways to the Future - Personal Needs. http://www.pathwayswv.org/personalneeds.php.

Personal Needs. Pathways to the Future - Personal Needs. http://www.pathwayswv.org/personalneeds.php.

U.S. News \& World Report. A Guide for Renting Your First Apartment. U.S. News \& World Report. https://money.usnews.com/money/blogs/my-money/2014/05/14/a-guide-forrenting-your-first-apartment. 


\section{Appendix M}

\section{Self-Care: Health Class}

\section{Self-Care}

By: Rupa Parikh, OTDS

- What comes to your mind when hearing the word self-care?

Go to www.menti.com and use the code 744455

- Self-Care in High School

- $\quad$ https://www.youtube.com/watch?v=gEHPTjMv4F0

- What is self-care?

Self-care is any activity that we do deliberately in order to take care of our mental, emotional, and physical health

Knowing what we need to do in order to take care of ourselves, being subsequently, able to take care of others as well

"If I don't take enough care of myself, I won't be in the place to give to my loved ones either"

- $\quad$ Self-Care Strategies for Overall Health

Get enough sleep, eat well, connect with others, engage in physical activity, develop coping skills

- $\quad$ Self-Care Strategies for Overall Health

Asking for help when needed, brightening your outlook, reducing stress, being mindful, good personal hygiene

References

Michael, R. (2018, July 8). What Self-Care Is - and What It Isn't. https://psychcentral.com/blog/what-self-care-is-and-what-it-isnt-2/. 


\section{Appendix N}

\section{Food \& Nutrition: Health Class Outline}

Food and Nutrition

By: Rupa Parikh, OTDS

- What is good nutrition?

Good food and nutrition provide our bodies with the fuel and energy we need throughout the day Good nutrition means giving your body all the vitamins, nutrients, and minerals it needs to work at its best

- The Numbers

About one-third of U.S. adults $(33.8 \%)$ are obese

Approximately $17 \%$ (or 12.5 million) of children and adolescents aged 2-19 years are obese

Even for people at a healthy weight, a poor diet is associated with major health risks that can cause illness and even death

- Benefits of good nutrition

Reduces the risk of some diseases such as diabetes, heart disease, stroke, and osteoporosis

Reduces high blood pressure

Lower high cholesterol

Increases in energy level

Increased ability to fight off illness

- What is MyPlate?

Tips on finding your healthy eating style

Focuses on variety, amount, and nutrition

The right mix of foods and drinks can help you be healthier now, and in the future 


\section{Mentimeter Time!}

Go to www.menti.com and use the code 219457

\section{- Healthy Snack Options}

First: Munchies that crunch

Second: Rethink your drink

Third: Snacks that satisfy

Finally: Snacks to curb your sweet tooth

- How to Understand and Use the Nutrition Facts Label

\section{- $\quad$ Serving Size}

Serving size is the amount of servings per container

The serving size reflects the amount that people typically eat or drink. It is not a recommendation of how much you should eat or drink

Pay attention to the serving size, especially how many servings there are in the food package. For example, you might ask yourself if you are consuming $1 / 2$ serving, 1 serving, or more In the sample label, one serving of lasagna equals 1 cup. If you ate two cups, you would be consuming two servings. That is two times the calories and nutrients shown in the sample label, so you would need to double the nutrient and calorie amounts, as well as the \%DVs, to see what you are getting in two servings.

\section{- Calories}

Calories refers to how much energy you get from a serving of this food or drink In the example, there are 280 calories in one serving of lasagna. What if you ate the entire package? Then, you would consume 4 servings, or 1,120 calories

2,000 calories a day is used as a general guide for nutrition advice 
Your calorie needs may be higher or lower and vary depending on your age, sex, height, weight, and physical activity level.

- Nutrients

Look for foods that contain more of the nutrients you want to get more of and less of the nutrients you may want to limit

Nutrients to get less of: Saturated Fat, Sodium, and Added Sugars

Nutrients to get more of: Dietary Fiber, Vitamin D, Calcium, Iron, and Potassium

Total Sugars on the Nutrition Facts label includes sugars naturally present in many nutritious foods and beverages, such as sugar in milk and fruit as well as any added sugars that may be present in the product.

- $\quad$ The Percent Daily Value (\%DV)

The $\% \mathrm{DV}$ is percent of the Daily Value for each nutrient in a serving of the food The Daily Values are reference amounts (expressed in grams, milligrams, or micrograms) of nutrients to consume or not to exceed each day The \%DV can tell you if a serving of food is high or low in a nutrient and whether a serving of the food contributes a lot, or a little, to your daily diet for each nutrient.

- Assignment Directions https://www.accessdata.fda.gov/scripts/InteractiveNutritionFactsLabel/\#intro References

Case-Lo, C. (806AD, April 10). Food \& Nutrition. Healthline. https://www.healthline.com/health/food-nutrition. Center for Food Safety and Applied Nutrition. How to Understand and Use the Nutrition Facts 
Label. U.S. Food and Drug Administration. https://www.fda.gov/food/new-nutrition-factslabel/how-understand-and-use-nutrition-facts-label.

Healthy Snacking. www.heart.org. https://www.heart.org/en/healthy-living/healthy-eating/addcolor/healthy-snacking.

The Importance of Good Nutrition: Tufts Health Plan Medicare Preferred. https://www.tuftsmedicarepreferred.org/healthy-living/expert-knowledge/importance-goodnutrition.

MyPlate Graphic Resources. ChooseMyPlate.

https://www.choosemyplate.gov/resources/myplate-graphic-resources.

US Department of Health and Human Services. (2017, January 26). Importance of Good Nutrition. HHS.gov. https://www.hhs.gov/fitness/eat-healthy/importance-of-goodnutrition/index.html. 


\section{Appendix O}

\section{Time Management: Health Class Outline}

Time Management

By: Rupa Parikh, OTDS

- $\quad$ Time Management

The ability to plan and control how much time you spend throughout the day to accomplish goals

- Mentimeter

"What strategies/tools do you use to help manage your time efficiently?

Go to www.menti.com and use the code 391059

- Time Management Strategies

Reduce clutter

Eliminate distractions

Know and set your limits

Make a schedule

List and prioritize

Know your energy levels

- Eliminate Distractions

Turn off notifications

Place your phone in a new spot

Use monitoring features on devices

Wear headphones

Think about your work environment

- Know and Set Your Limits 
- Make a Schedule

Enter your priorities first, be realistic, prepare for problems, make time to relax, do it

- $\quad$ List and prioritize

Arrange items in order of importance

You may not be able to do everything on your list. However, if you put the most important items

first, you can be sure to get them done

Prioritizing also helps you decide which activities can be eliminated

- The Eisenhower Matrix

- Know your energy levels

- How to beat the procrastination cycle

Part 1: If the task can be completed in 2 minutes...DO IT NOW

Part 2: If the task will take longer than 2 minutes...START IT for 2 minutes 


\section{Appendix P}

\section{Stress Management: Health Class Outline}

Stress Management

By: Rupa Parikh, OTDS

- What Causes Stress?

Stress: The body's and mind's response to a demand

Stressors: Any situation that puts a demand on the body or mind. There are several different types of stressors

1. Environmental Stressors

2. Biological Stressors

3. Thinking Stressors

4. Behavioral Stressors

5. Life Change Stressors

- Physical Response to Stress

Fight-or-Flight Response: Your body provides you with the energy, reflexes, and strength you may need to respond to the stressor

Your body releases the hormone epinephrine (adrenaline) as a part of the response

Epinephrine prepares the body for quick action by triggering the following changes:

1) Your breathing speeds up, which helps get more oxygen through your body

2) Faster heartbeat increasing blood flow to carry more oxygen to your muscles

3) Your muscles tense up, which prepares you to move quickly

4) The pupils of your eyes get wider, which allows extra light for more sensitive vision

5) Your digestion stops, since this is an unnecessary activity during an emergency 
6) Blood sugar increases to provide more fuel for fighting or running

- Emotional and Behavioral Response to Stress

\section{$\underline{\text { Positive Stress }}$}

Positive stress can help you respond well in a stressful situation

A positive stress that energizes one and helps one reach a goal is called eustress

Eustress will make you feel alert and lively. You will appear confident and in control

\section{$\underline{\text { Negative Stress }}$}

Distress is negative stress that can make a person sick or keep a person from reaching a goal Distress can keep you from doing your best, no matter how capable you are

- Negative Effects of Chronic Stress

Chronic Stress: Stress that lasts for a long period of time. Chronic stress can go on for weeks, months, or years

This type of long-lasting stress can lead to many health problems

The general adaptation syndrome is a model that describes the relationship between stress and disease

1. Alarm Stage: In the alarm stage, the body and mind become alert. This stage includes the events brought on by the fight-or-flight response. All of your body's efforts go into responding to the demand. A person in this stage may experience headaches, stomachaches, difficulty sleeping, and anxiety.

2. Resistance Stage: If the stress continues, your body becomes more resistant to disease and injury than normal. You can cope with added stress, but only for a limited time.

3. Exhaustion Stage: In this stage, your body cannot take the resistance to the stressor any longer, especially if several stressors occur in a row. You become exhausted, not in the 
normal sense like after along, busy day, but in a more serious way. Organs such as your heart may suffer, and your immune system can no longer fight illness.

- Causes of Stress for Students

Exams, deadlines, combination of work and school, difficulty in organization, poor time management, debt, housing problem, adjusting to a new environment, balance of social life and studying, difficulties with personal relationships

- Stress Management Techniques

Think positively, look after yourself, confront the problem, find some distraction, express yourself

- Learn to Relax

Breathing exercises, tension-relaxing exercises

- $\quad$ Build Resiliency

Resiliency: The ability to recover from illness, hardship, and other stressors

Many resilient people get their strength from their assets

An asset is a skill or resource that can help you reach a goal. For example, support is an asset

References

Friedman, D. P., Stine, C. C., \& Whalen, S. (2009). Lifetime health. Holt, Rinehart and Winston.

Stress and your health: MedlinePlus Medical Encyclopedia.

https://medlineplus.gov/ency/article/003211.htm.

Stress Management: Breathing Exercises for Relaxation. Stress Management: Breathing Exercises for Relaxation | Michigan Medicine. https://www.uofmhealth.org/healthlibrary/uz2255.

University of St Andrews. Managing Stress | Current Students | University of St Andrews. 
https://www.st-andrews.ac.uk/students/advice/leaflets/stress/. 


\title{
Appendix Q
}

\section{Life Skills Inventory Independent-Living Skills Assessment Tool}

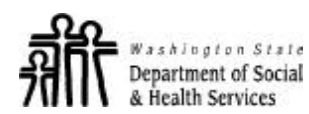

\author{
CHILDREN'S ADMINISTRATION \\ DIVISION OF CHILDREN AND FAMILY SERVICES \\ LIFE SKILLS INVENTORY \\ INDEPENDENT LIVING SKILLS ASSESSMENT TOOL
}

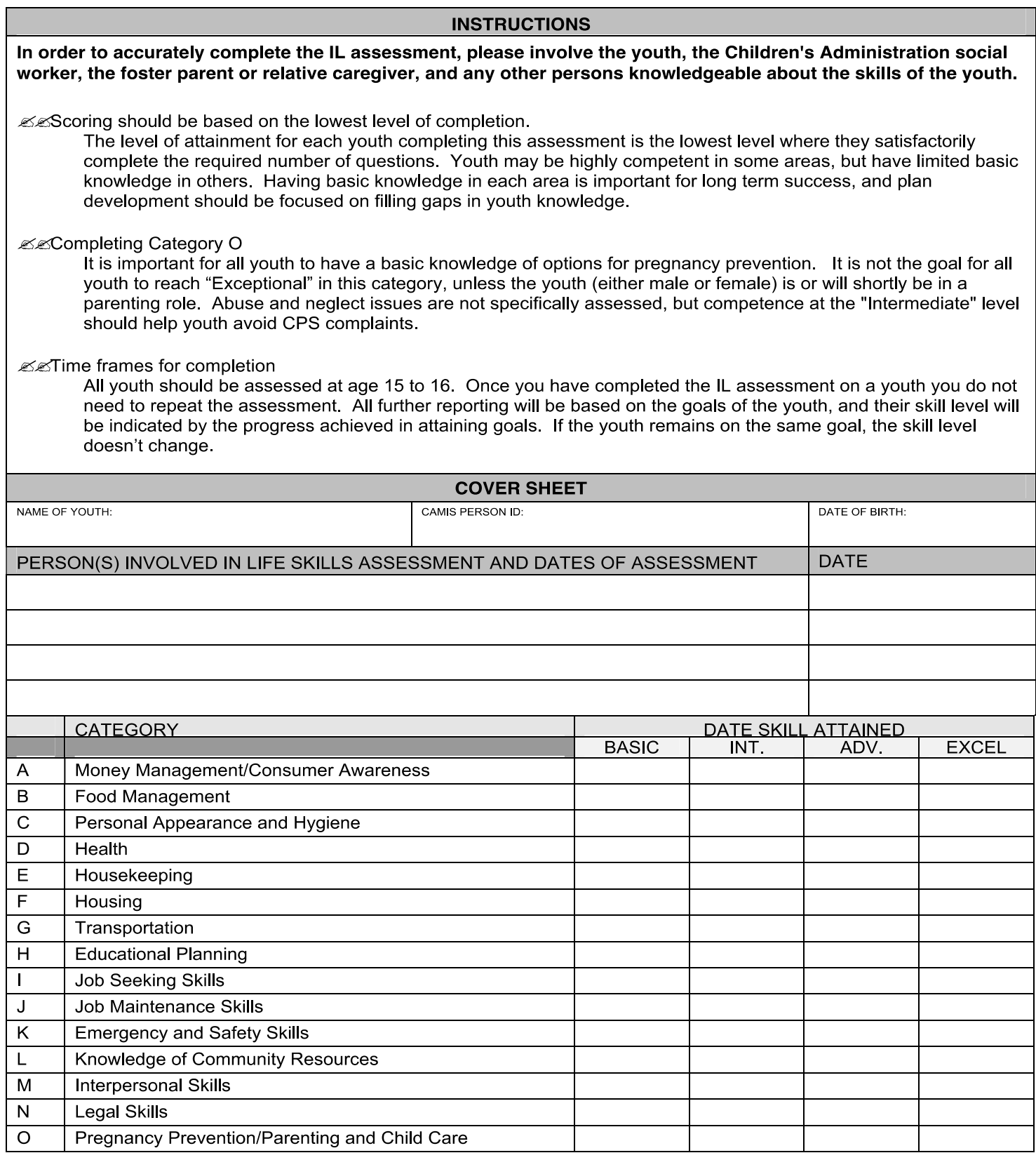


Category A: Money Management and Consumer Awareness

Basic - Must know 3 of 5 to advance to the next level of accomplishment:

Knows values of coins and currency.

Can make a transaction at a local store and count change.

Has an understanding of the difference between "luxuries" and "necessities" in food, transportation, clothing, housing. Understands the difference between "sale price" and "regular price".

Can identify one way to save money on purchases.

Intermediate - Must know 4 of 6 to advance to the next level of accomplishment:

Can open a checking or savings account.

Can write checks/make withdrawals and make deposits.

Can record banking transactions (either checking or savings).

Can budget allowance to last for a week. (Shows some understanding of the concept of saving).

Understands the difference between gross wage and take home pay.

Can use a calculabr to add. subtract. divide and multiolv.

Advanced - Must know 4 of 6 to advance to the next level of accomplishment:

With assistance can make out monthly budget covering regular expenses for independent living.

Shows some "sales resistance" to "something for nothing" advertising and "low weekly payment" credit plans.

Can read monthly bank statements, compare balances, make adjustments as necessary (deduct service charges, check fees, adjust for differences in the balance).

Can comparison shop using unit pricing information.

Understands the responsibility of filing tax forms. Knows the information that is required for filing taxes and knows where to go to get assistance in filing taxes.

Knows how to clip and use coupons.

Exceptional - Must know at least 3 to be rated as exceptional:

Budgets for unanticipated emergencies, seasonal bills, etc.

Understands buying on credit, loans, interest, and late payment penalties.

Understands payroll deductions, taxes, FICA, insurance.

Can complete a short tax form.

Can balance a checkbook.

Has reqular savings proqram.

\section{Category B: Food Management}

Basic - Must know at least 3 of 4:

Washes hands before eating and preparing food.

Can order in a cafeteria or fast food restaurant.

Can describe food pyramid and foods that contribute to a healthy life style.

Knows name and use of cookina utensils.

Intermediate - Must be able to do 5 of 8 :

Can order a meal from the menu in a restaurant

Can fix a breakfast for one

Can fix a lunch for one

Can fix a dinner for one

Can make out a grocery shopping list

Can use cooking utensils effectively and safely (knives, grater, can opener, potato peeler, egg beater, etc.)

Can use kitchen appliances effectively and safely

Can use acceptable table manners

Advanced - Must know 5 out of 7:

Stores perishable items under refrigeration.

Recognizes signs of spoilage in food.

Can follow the instructions for preparing canned or frazen foods.

Can plan weekly menu of nutritious meals.

Can shop for a week's menu and stay within a food budget.

Can set the table properly.

Can carrv out a arocerv-shopoina trid (selectina items on the shoopina list and pavina the cashier).

Exceptional - Must know at least 3:

Prepares recipes from a cookbook.

Can adjust recipes to feed more or less people than called for in the recipes.

Understands how to use dates on food packages b prevent spoilage. (see next page) 


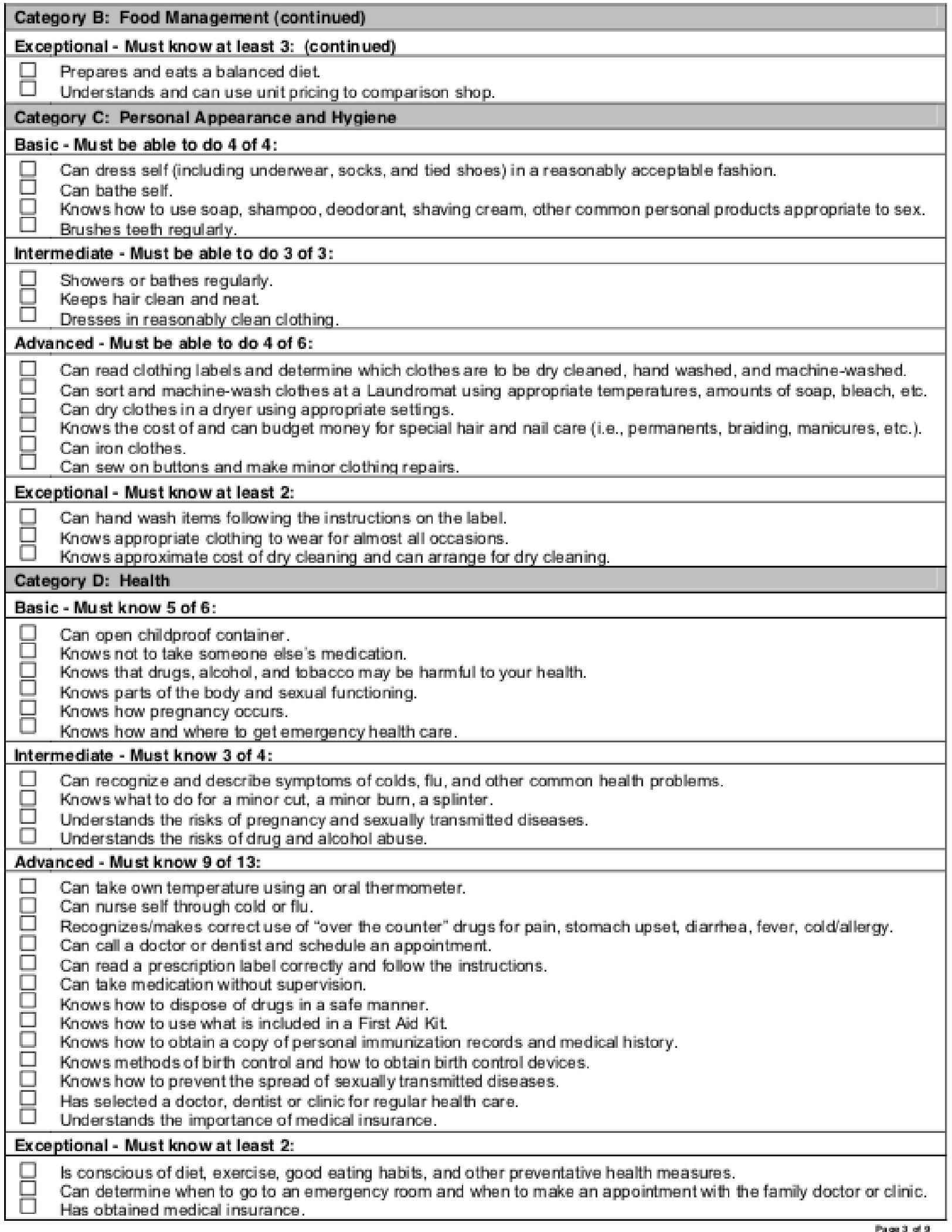




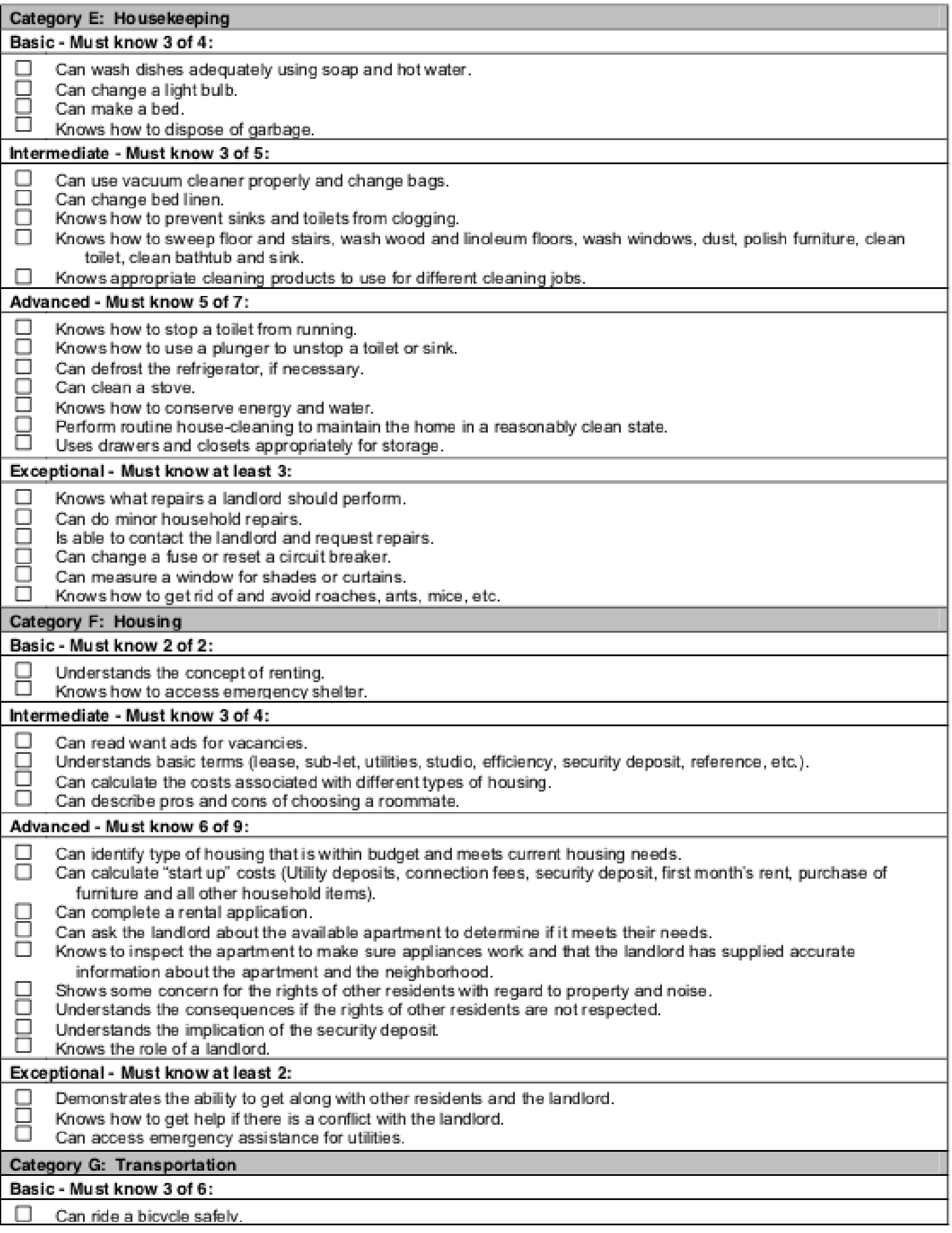




\section{Category G: Transportation (continued)}

Basic - Must know 3 of 6: (continued)

$\square$ Understands and uses seat belts.

Familiar with any form of public transportation available.

Knows the nearest public bus stop to your home.

Knows amount of money required for bus fare.

Knows the nearest town with bus services.

\section{Intermediate - Must know 3 of 6 :}

Aware of consequences of driving without a license and insurance.

Has successfully completed a Driver's Ed class.

Knows how to call a taxi and provide information needed. Knows the approximate cost of taking a taxi.

If given instructions, can make public transportation journey involving several transfers.

Knows requirements for foster parent reimbursement for providing transportation.

Can give directions.

\section{Advanced - Must know 4 of 5 :}

Can arrange routine transportation to work or school.

Knows what is required to get a driver's license.

Has driver's permit.

Can fix a bicycle.

Can read a map.

\section{Exceptional - Must know 2 of 3 :}

Knows how to do basic car maintenance.

Can estimate cost of owning and operating a car for a month/year including tabs and insurance.

Has a driver's license.

\section{Category $\mathrm{H}$ : Educational Planning}

\section{Basic - Must know 2 of 2:}

Has a realistic view of his/her chances for completing high school.

If high school graduation is not realistic, understands what a GED is and how to obtain one.

\section{Intermediate - Must know 3 of $\mathbf{4}$ :}

Can fill out forms to enroll in an educational program.

Has a general idea of what education is needed for the job he/she wants.

Can discuss educational/vocational plans with teachersicounselor.

Is aware of educational resources available in the communitv.

\section{Advanced - Must know 4 of 6 :}

Knows how to obtain school transcripts.

Is aware of current educational credits and standing.

Has an appropriate educational plan for the job selected.

Understands educationalskill requirements for job selected.

Is aware of the cost of higher education/vocational training.

Knows the difference between a loan and a grant.

\section{Exceptional - Must know at least 3:}

"Shops around" to find the best educational resources.

Knows where to find and how to access adult education or vocational training in the community.

Knows how to obtain financial aid/scholarships for additional education.

Understands future prospects and probable living standards relative to levels of education and specialized skills.

Is able to identify the connection between course work and vocational goals.

\section{Category I: Job Seeking Skills}

\section{Basic - Must know 2 of 2:}

Has reasonable idea of the types of jobs available to him/her.

Knows what the minimum wage is.

\section{Intermediate - Must know $\mathbf{4}$ of 5:}

Can fill out a standard job application form.

Can read the want ads and find appropriate leads.

Can complete a mock interview giving appropriate answers to potential questions.

(see next dage) 


\section{Category I: Job Seeking Skills (continued)}

Intermediate - Must know 4 of 5 : (continued)

Can make appointment for a job interview.

Knows appropriate clothing to wear for the interview.

\section{Advanced - Must know 6 of 8 :}

Can write a resume.

Has a completed job application/fact sheet to take on a job interview.

Knows to prepare for a job interview.

Can complete a job interview.

Knows the function of and can contact the public employment agency.

Knows the function of and understands that private employment agencies charge fees.

Can identify ads placed by private employment agencies.

Can contact temborarvemolovment services.

\section{Exceptional - Must know at least 2:}

\section{Has a resume.}

Can follow up an interview with a letter.

is able to maturely weigh the advantages of one job over another.

Understands legal discrimination and where to seek help if discriminated against illegally.

\section{Category J: Job Maintenance Skills}

\section{Basic - Must know 3 of 4 :}

Dresses for work appropriately.

Reports to work on time.

Knows job responsibilities and how to complete job tasks.

Knows to contact employer when not able to go to work.

\section{Intermediate - Must know 3 of $\mathbf{4}$ :}

Know how to read a pay stub.

Knows appropriate way to talk to supervisor.

Knows what behaviors will get a person fired immediately.

Knows how to ask for help with a problem on the job.

\section{Advanced - Must know $\mathbf{4}$ of $\mathbf{5}$ :}

Knows if eligible for sick time, vacation time, or personal time.

Knows what a grievance procedure is.

Know what to do to get a raise.

Knows where and when not b talk with co-workers.

Has a plan for handling anger when angrv at supervisor, co-workers, or customers.

\section{Exceptional - Must know at least 3:}

Can implement anger management plan in majority of cases.

Knows how to use company grievance procedure to resolve disagreements.

Knows companies "unwritten policies" and can function within them.

Knows how to ask for a raise.

Knows what to do to be eligible for promotion.

Knows legal rights as an employee.

\section{Category K: Emergency and Safety Skills}

\section{Basic - Must know 4 of 5 :}

Knows functions of police, ambulance and fire department. Can reach each by calling the appropriate number. Is trained to evacuate the residence in case of fire.

Knows proper way of disposing of smoking materials, if smokes.

Knows how to lock and unlock doors and windows.

Knows how to check smoke alarm and how to replace battery.

\section{Intermediate - Must know $\mathbf{3}$ of $\mathbf{5}$ :}

Understands basic fire prevention (No smoking in bed, using gas stove to heat, excessive use of extension cords,

frayed electrical cords, etc.).

Knows how to use a fire extinguisher.

Knows that improperly used appliances can cause fires.

Can recognize the smell of a gas leak.

(see next page) 


\begin{tabular}{|c|c|}
\hline \multicolumn{2}{|r|}{ Intermediate - Must know 3 of 5: (continued) } \\
\hline$\square$ & Knows what to do, and whom to call if she/he smells a gas leak. \\
\hline \multicolumn{2}{|c|}{ Advanced - Must know 2 of 3: } \\
\hline $\begin{array}{l}\square \\
\square\end{array}$ & $\begin{array}{l}\text { Knows the different methods for putting out different kinds of fires. } \\
\text { Knows how to properly store cleaning materials. } \\
\text { Can usually determine when professional medical help is needed. }\end{array}$ \\
\hline \multicolumn{2}{|c|}{ Exceptional - Must know 2 of 2: } \\
\hline$\square$ & $\begin{array}{l}\text { 'Youth may have their cards, but completion of the other areas is important. The rating should be based on } \\
\text { the lowest area where they have completed the skills. } \\
\text { Has completed First Aid training. } \\
\text { Has completed CPR training. }\end{array}$ \\
\hline \multicolumn{2}{|r|}{ Category L: Knowledge of Community Resources } \\
\hline \multicolumn{2}{|c|}{ Basic - Must know 4 of 5 : } \\
\hline $\begin{array}{l}\square \\
\square \\
\square \\
\square\end{array}$ & $\begin{array}{l}\text { Knows how to get emergency information by telephone. } \\
\text { Knows whom to contact if injured or sick. } \\
\text { Knows where nearest supermarket or shopping district is located. } \\
\text { Knows how to access emergency food and shelter. } \\
\text { Knows how to access crisis line. }\end{array}$ \\
\hline \multicolumn{2}{|c|}{ Intermediate - Must know 3 of 5 : } \\
\hline $\begin{array}{l}\square \\
\square \\
\square \\
\square\end{array}$ & $\begin{array}{l}\text { Knows where nearest Laundromat is located. } \\
\text { Knows where personal bank is located. } \\
\text { Can use the yellow pages to obtain information. } \\
\text { Knows location of nearest CSO. } \\
\text { Knows location of nearest post office and how to use it. }\end{array}$ \\
\hline \multicolumn{2}{|r|}{ Advanced - Must know 3 of 5 : } \\
\hline $\begin{array}{l}\square \\
\square \\
\square \\
\square\end{array}$ & $\begin{array}{l}\text { Knows whom to contact if utilities disconnected, or heat goes out. } \\
\text { Knows where and how to register for selective service. } \\
\text { Knows where the nearest state employment office is located. } \\
\text { Can obtain a copy of birth certificate and a duplicate social security card. } \\
\text { Has awareness of "specialized" resources: mental health counseling, consumer counseling, VD clinics, student aid } \\
\text { offices, tenant groups, animal control, public recreation, etc. }\end{array}$ \\
\hline \multicolumn{2}{|r|}{ Exceptional - Must know at least 2: } \\
\hline$\square$ & $\begin{array}{l}\text { Knows who elected representatives are and how to contact them. } \\
\text { Has obtained a library card. } \\
\text { Knows what the Better Business Bureau does and how to contact it. }\end{array}$ \\
\hline \multicolumn{2}{|r|}{ Category M: Interpersonal Skills } \\
\hline \multicolumn{2}{|c|}{ Basic-Must know 5 of 5 : } \\
\hline $\begin{array}{l}\square \\
\square \\
\square \\
\square\end{array}$ & $\begin{array}{l}\text { Can respond to introductions and answer simple questions. } \\
\text { Can identify one friend. } \\
\text { Look others in the eye and shakes hands if other person offers. } \\
\text { Can make "small talk" (face b face). } \\
\text { Communicates with at least one person weekly. }\end{array}$ \\
\hline \multicolumn{2}{|r|}{ Intermediate - Must know 4 of 6 : } \\
\hline $\begin{array}{l}\square \\
\square \\
\square \\
\square\end{array}$ & $\begin{array}{l}\text { Can make introductions, including approaching others to introduce self. } \\
\text { is aware of boundary issues. } \\
\text { is not harmful to others. } \\
\text { Can ask for help. } \\
\text { Can explain feelings. } \\
\text { Can identify relationships that may be hurtful or dangerous. }\end{array}$ \\
\hline \multicolumn{2}{|c|}{ Advanced - Must know 8 of 13: } \\
\hline $\begin{array}{l}\square \\
\square \\
\square\end{array}$ & $\begin{array}{l}\text { Can identify personal strengths and needs (with assistance if necessary). } \\
\text { Accepts invitations from others to be involved in social activities. } \\
\text { Make arrangements with peers for social activities. } \\
\text { (see next page) }\end{array}$ \\
\hline
\end{tabular}


Category M: Interpersonal Skills (continued)

Advanced - Must know 8 of 13: (continued)

$\square$ Knows where to get help if unable to resolve interpersonal conflicts alone.

$\square$ Has some ability bo resolve conflicts with others.

Refrains from physical violence as a means of solving interpersonal conflict.

Has practiced how to say "no" to a peer who is trying to persuade him/her to do something wrong.

Can develop a realistic plan with appropriate steps identified to achieve goals.

$\square$ Can carry out plans with some assistance provided.

Can describe the "best possible" outcome if the goal is achieved and the "worst possible" outcome if the goal is not achieved.

Can describe the relationship between actions and consequences.

Has "good" table manners (can use knife, fork, spoons, napkin appropriately).

Avoids hurtful or dangerous relationships.

\section{Exceptional - Must know at least 3:}

Labels and expresses anger or other strong feelings appropriately, "talks ouf' problems.

Has demonstrated the ability to say "no" b peers.

Can develop and carry out a personal plan for goal achievement without supervision.

Can anticipate, with limited input from others, what consequences might be associated with different choices.

Knows when and how to send written thank-you notes.

Can close a relationship or say "good bye" in a healthy manner.

\section{Category N: Legal issues}

Basic - Must know 2 of 2:

Has the phone number of someone to call if arrested or victimized.

Understands generally what actions are against the law and what the consequences are.

\section{Intermediate - Must know $\mathbf{4}$ of $\mathbf{7}$ :}

Knows personal rights if arrested.

Knows what the function of a lawyer is.

Knows legal age for buying alcohol and tobacco products.

Understands the meaning of "legal age" in legal terms (what you can do, what you cannot do).

Knows how to read a contract.

Has understanding of dependency process.

Knows how and where to reqister to vote.

\section{Advanced - Must know 3 of $\mathbf{4}$ :}

$\square$ Knows the responsibility to register for selective service, if male.

Aware of availability of free legal services.

Understands the consequences of signing a contract or a lease.

$\square$ Knows the legal penalty for all of the following:

$\square \quad$ Buying, possessing, selling, and smoking marijuana and other drugs

$\square \quad$ Buying and drinking beer and alcohol underage

$\square \quad$ Trespassing

Shoplifting

Burglary

Possession of stolen property

Traffic violations

\section{Exceptional - Must know at least 2:}

Show good citizenship and an understanding of the rights and responsibilities of a citizen.

is registered to vote.

Knows where to go to vote.

Knows the difference between "felony", "misdemeanor", and "violation".

Category O: Pregnancy, Parenting and Child Care

Basid/Pregnancy - Must know 6 of 6: (All youth complete this part)

Knows resources for birth control.

Knows location of family planning office.

Knows options for birth control.

Knows options for pregnancy. (see next page) 
Category O: Pregnancy, Parenting and Child Care (continued)

Basic/Pregnancy - Must know 6 of 6: (All youth complete this part) (continued)

Knows dangers of drugs, alcohol, and tobacco during pregnancy.

Knows what adequate pre-natal care is.

Intermediate/Parenting and Child Care - Must know 10 of 10: (Pregnant or parenting teens)

Knows where to obtain pre-natal care.

Knows not to leave child without supervision.

Can provide appropriate supervision for child.

Is comfortable being alone with child.

Knows how to bathe child and change diapers.

Knows how to access community resources (WIC, PHN).

Knows how to engage child in appropriate play (reading, singing, drawing, building things, etc.).

Knows the available options for regular childcare.

Selects appropriate people to periodically baby-sit with child.

Knows where to go for help if child is sick.

Advanced - Must know 5 of 6: (Pregnant or parenting)

Can select toys appropriate for child's age and developmental level,

Can discipline without using extreme measures (hitting, screaming, with holding necessary food or care).

Can make arrangements for regular childcare.

Takes child to childcare on time. Picks child up from childcare on time.

Spends "quality" time with child each day (talking, playing together, listening to the child, etc.). Knows where to go for help with parenting.

Exceptional

Knows what behaviors are appropriate for the child's age and developmental level.

Knows the costs and benefits of each child care arrangement available. 